\title{
Quantified concealed questions
}

\author{
Ilaria Frana
}

Published online: 16 January 2013

(C) The Author(s) 2013. This article is published with open access at Springerlink.com

\begin{abstract}
This paper presents a novel treatment of quantified concealed questions (CQs), examining different types of NP predicates and deriving the truth conditions for pair-list and set readings. A generalization is proposed regarding the distribution of the two readings, namely that pair-list readings arise from CQs with relational head nouns, whereas set readings arise from CQs whose head nouns are not (or no longer) relational. It is shown that set readings cannot be derived under the 'individual concept' approach, one of the most influential analyses of CQs on the market. The paper offers a solution to this problem. It shows that once we adopt an independently motivated view of traces-according to which traces are copies with descriptive content (Fox, Linguist Inq 30:157-196, 1999; Fox, Linguist Inq 33:63-96, 2002)—nothing else needs to be postulated to derive set readings within an individual-concept-based analysis. Thus, what seemed to be a challenge for this type of analysis turns out to be an argument in its favor.
\end{abstract}

Keywords Concealed questions · Individual concepts · Attitude ascriptions · Descriptive traces

\section{Introduction}

Concealed questions (henceforth, CQs) are DPs whose interpretation can be paraphrased by an embedded identity question. An example of a definite DP with a CQ interpretation is given in (1) below.

I. Frana $(\bowtie)$

Sprachwissenschaftliches Seminar, Georg August-Universität Göttingen, Käte-Hamburger-Weg 3, 37073 Göttingen, Germany

e-mail: frana@linguist.umass.edu 
(1) Sue found out the gender of her baby.

(= Sue found out what the gender of her baby was)

CQs are also possible with quantified DP objects. Interestingly, such cases are often ambiguous. As pointed out by Heim (1979) (see also Roelofsen and Aloni 2008), the sentence in (2) below can have two readings. ${ }^{1}$ According to one reading- the pair-list reading - the sentence says that for every existing country $x$, Mary knows the answer to the question 'What is the capital of $x$ ?'. According to the other reading - the set reading - the sentence says that for every existing capital city $z$, Mary knows the answer to the question 'Is $z$ a capital?', or 'Is $z$ the capital of some country?'. Crucially, under this second reading, the attitude holder does not have to know how to match each capital city to the corresponding country. The readings just described are truth-conditionally different. In fact, it is easy to imagine scenarios that would make the set reading true but the pair-list reading false. (The reverse does not hold: i.e., the pair-list reading entails the set reading, but not the other way around.)

(2) Mary knows every capital.

Pair-list reading: For every country $x$, Mary knows what the capital of $x$ is. Set reading: $\quad$ For every capital city $z$, Mary knows that $z$ is a capital.

The ambiguity displayed by (2) is quite systematic; in fact, it is found whenever the head noun of the quantified CQ is relational. Further examples are provided in $(3 a, b)$.

(3) a. The secretary knows every phone number (of the employees in this office). b. The postman knows every zip code (in Massachusetts).

The examples in (3a) (from Heim 1979) and (3b), with the relational nouns phone number and zip code, are ambiguous in the same way (2) is. Under one reading of (3a), the secretary knows for every employee in this office what his/her phone number is (pair-list reading). However, this is not the only reading available. Imagine that the secretary needs to assign to a new employee a phone number that is not yet taken by any other employee. In this case, she "needs to know every phone number not in the sense of knowing which number is whose, but merely in the sense of knowing which numbers are somebody's at all" (Heim 1979). Similarly for (3b). Under one reading, the postman knows for every town in Massachusetts what its zip code is (pair-list reading). Under the other reading, he simply knows for every actual zip code from Massachusetts that it is the zip code of some town in Massachusetts (set reading).

The goal of this paper is to provide an analysis of quantified CQs which derives the truth conditions of pair-list and set readings. With respect to the distribution of the two readings, I propose the following generalization:

\footnotetext{
1 I am setting aside for the moment another reading of (2), according to which Mary bears some relation of acquaintance to every capital city. I will return to acquaintance-based readings in Sect. 2.1.
} 
(4) Distribution of pair-list and set readings:

Pair-list readings arise with CQs headed by relational nouns whose internal argument has not been saturated (2-place predicate NPs; semantic type $<\mathrm{e}<\mathrm{e}, \mathrm{t}>>$ ). Set readings arise with CQs headed by nouns that are not-or no longer-relational (1-place predicate NPs; semantic type <e,t $>$ ).

In support of the claim that set readings correlate with 1-place predicate NPs, consider the data in (5)-(6) below. In (5), the head noun of the CQ is lexically not relational, whereas in (6) the head noun of the CQ is lexically relational but its internal argument has been saturated. In both cases, the NP-CQ denotes a 1-place predicate (semantic type $<\mathrm{e}, \mathrm{t}>$ ) and the sentences are preferably interpreted as having set readings. ${ }^{2}$

(5) Julio knows every book that Rita read this summer.

$C Q$ set reading: For every actual book $x$ that Rita read this summer (Anna Karenina, Les Misérables, etc.) Julio knows that $x$ is a book that Rita read this summer.

(6) Bob knows every member of the Italian soccer team.

$C Q$ set reading: For every actual member $x$ of the Italian soccer team (Pirlo, Buffon, etc.), Bob knows that $x$ is a member of the Italian soccer team.

However, one may be wondering, if the generalization stated in (4) is correct, why are sentences with 2-place NP-CQs, like (2) and (3), still ambiguous? Shouldn't they have just pair-list readings? I propose that the ambiguity of sentences with 2-place NP-CQs follows from the fact that relational nouns, just like transitive verbs, can occur as either transitive (2-place: $<\mathrm{e}<\mathrm{e}, \mathrm{t}\rangle>$ ) or intransitive (1-place: $<$ e,t $>$ ) predicates (cf. Barker 1995; Partee 1983/1997, a.o.), with the first type generating pair-list readings and the second set readings.

The account of quantified CQs I propose is cast within the 'individual concept' approach (henceforth, IC-approach). ${ }^{3}$ I start by showing that the version of the IC-approach provided by Heim (1979) and Romero (2005) to account for definite CQs can be extended to quantified CQs with functional nouns (pair-list readings). This is implemented by allowing quantification over meaningfully sorted concepts (cf. Nathan 2006). Quantification over suitable concepts, however, cannot be the

\footnotetext{
2 It is possible to contextually force a relational interpretation of the noun and make pair-list readings available in these cases too. For example, member of the Italian soccer team could be interpreted as a function mapping each individual member of the team to the role he plays as a member of the team. Under this interpretation of the noun, it is possible to generate a pair-list reading according to which Bobo has to know for each individual what his role in the team is. However, when the noun is interpreted as a 1-place predicate, the sentence only has a set reading.

3 A different account of quantified CQs within the IC-approach is given in Romero (2010). A comparison with Romero's analysis is left for future research.
} 
right tool to account for set readings, which involve quantification over individuals. I argue that the challenge presented by set readings and, more generally, by CQs headed by nouns that are neither functional nor relational can be overcome within an IC-based approach if we adopt an independently motivated view of traces (Fox 1999, 2002). Once we adopt the view that traces are copies with descriptive content, nothing else needs to be said to derive set readings within the IC-approach. Thus, what seemed to be a challenge for this type of analysis turns out to be an argument in its favor. In the last part of the paper, I return to pair-list readings to show that quantification over suitable concepts cannot account for pair-list readings with nouns that are relational but not functional. Such cases, I argue, require quantification over pairs of individuals, rather than concepts.

The paper is structured in the following way. Section 2 introduces the ICapproach for simple definite CQs (Heim 1979; Romero 2005). Section 3 extends Heim/Romero's IC-approach to quantified CQs with functional nouns (pair-list readings). Section 4 shows that the extended version of the IC-approach cannot account for quantified CQs with set readings. Section 5 proposes a solution to this problem by showing that set readings can be derived within an IC-based approach by assuming the copy theory of movement and a mechanism for interpreting copy traces along the lines of Fox's trace conversion. Section 6 addresses pair-list readings with nouns that are relational but not functional, which require one further amendment to the original IC-approach.

\section{Definite CQs and the individual concept approach}

\subsection{Background: Acquaintance and CQ-readings}

Some examples of definite DPs with CQ-readings are given in (7) below.

(7) a. She found out the murderer without going to the CSI forensic lab.

$\mathrm{a}^{\prime}$. She found out who the murderer was without going to the CSI forensic lab.

b. Ruben knows Eva's phone number.

$b^{\prime}$. Ruben knows what Eva's phone number is.

c. Paula knows Luis's favorite city.

$\mathrm{c}^{\prime}$. Paula knows what Luis's favorite city is.

Notice that while sentences $(7 \mathrm{a}, \mathrm{b})$ feel unambiguous, $(7 \mathrm{c})$ has another reading aside from its CQ-paraphrase in $\left(7 c^{\prime}\right)$. Under this other interpretation, the sentence says that Paula bears some relation of familiarity to a certain city, which happens to be Luis's favorite city. Crucially under this reading, which I will call the acquaintance reading, Paula does not have to know that the city in question is Luis's favorite city (i.e. the DP-object can have an epistemically neutral interpretation). Since Heim (1979), it is commonly assumed that the ambiguity between CQ and acquaintance readings of sentences like (1c) is due to the fact that the English predicate know is ambiguous between an intensional (epistemic) predicate know $w_{1}$ and an extensional 
(non-epistemic) predicate nnow $_{2}{ }^{4,5}$ Acquaintance readings correlate with the use of extensional know $_{2}$. Such cases are unproblematic and their interpretation can be derived in a way analogous to (8).

(8) Ruben dialed Eva's phone number.

Obviously, for (8) to be true Ruben does not have to know that the number he dialed is Eva's phone number (the DP-object can be epistemically neutral). Similarly, under the acquaintance reading of (7c), Paula may be personally acquainted with Luis's favorite city without knowing that it is in fact Luis's favorite city.

While acquaintance readings follow straightforwardly from basic principles of semantic composition, CQ-readings are much more challenging. In $(7 \mathrm{a}-\mathrm{c})$, I paraphrased each underlined CQ with an embedded question. Is this just a useful way to describe their meaning intuitively, or should we say that, although they surface as DPs, CQs are actually questions at some deeper level of representation? If not, how can we account for their apparent question-like meanings?

Over the past forty years, a range of accounts has been proposed for the interpretation of CQs with definite DPs. According to some approaches inspired by Grimshaw (1979), the denotation of a CQ must be shifted into the denotation of the corresponding copular question (through an especially devised type-shifter). Under this type of approach a sentence like (7b) above is analyzed along the lines of (9a). Romero (2007) and Nathan (2006), on the other hand, argue that CQs must be shifted into propositions and that a CQ-sentence like (7b), should be analyzed along the lines of (9b). Frana (2006) and Schwager (2008) argue that CQs denote properties and that a CQ-reading expresses a de re belief ascription, with the DP-CQ providing both the individual (res) argument and the property ascribed to it by the holder of the attitude (9c), linking the analysis of CQs to the factivity of the embedding predicate (Kratzer 1990, 2002). Finally, Heim (1979) entertains the hypothesis, later developed by Romero (2005), that CQs denote individual concepts (functions from indices to individuals) and that a CQ-sentence like (7b) should be

\footnotetext{
${ }^{4}$ As noted in the literature (Heim 1979; Romero 2005, a.o.), the lexical ambiguity hypothesis is supported by the fact that other languages distinguish between two different predicates corresponding to know; e.g. German wissen/kennen, Spanish saber/conocer, and Italian saperelconoscere. When wissen/ saber/sapere are allowed to take a DP-object, the sentence cannot receive an acquaintance reading. This is shown in (i) below for Italian:

(i) Gianni sa la capitale del Congo. *acquaintance

'Gianni knows the capital of Congo.' (= 'Gianni knows what the capital of Congo is')

5 The reason why (7a) is not ambiguous is because find out, unlike know (but like other predicates such as guess or predict), is unambiguously epistemic. As for (7b), an acquaintance reading is presumably made implausible by the fact that people are not normally acquainted with abstract objects like numbers - at least not in a way that would license the use of the acquaintance-based know 2 . The Italian sentence in (i) below with conoscere is marked, unless it is made clear from the context that the number is used as a device to identify a person (e.g. a prisoner).
}

(i) \#Luisa conosce 01762254

'Luisa knows 01762254.' 
analyzed along the lines of (9d). ${ }^{6}$ As suggested by the paraphrases below, all the existing approaches, although conceptually different, produce equivalent truth conditions for simple CQ-sentences with definite descriptions, like our examples in $(7 \mathrm{a}-\mathrm{c}){ }^{7}$

(9) Type-logical classification of CQ-analyses

a. CQs as questions: Ruben knows what Eva's phone number is. (Harris 2007; Aloni 2008; Roelofsen and Aloni 2008; Percus 2009, 2010)

b. CQs as propositions: Ruben knows that Eva's phone number is what Eva's phone number actually is. (Romero 2007; Nathan 2006)

c. CQs as properties: Ruben believes de re of Eva's actual phone number that it is Eva's phone number. (Frana 2006; Schwager 2008)

d. CQs as individual concepts: The value that the individual concept 'Eva's phone number' yields at the actual world and at Ruben's belief worlds is the same. (Heim 1979; Romero 2005; Frana 2010)

In this paper, I will frame my account of quantified CQs within an individualconcept-based analysis. Heim (1979) suggests that definite descriptions with CQ-readings, like the underlined DP in (10), may be analyzed on a par with definite descriptions in temporally intensional contexts, like the underlined DP in (11).

(10) Julio knows the temperature in this room.

(11) The temperature in this room is rising.

While in (11), the temporally intensional predicate is rising forces us to look at temperature values at earlier and later (temporal) indices, the epistemic predicate know in (10) forces us to compare temperature values at different (world) indices (the actual world $w$ and the worlds according to John's beliefs in $w$ ). Given the Montagovian treatment of sentences like (10) in terms of individual concepts (Montague 1974), Heim suggests that an analogous analysis could be given for (10).

\subsection{Definite CQs as individual concepts}

The original argument for the introduction of individual concepts is due to Montague's (1974) analysis of the temperature paradox, attributed to Barbara Partee. Partee's observation is that in contrast to the valid argument in (12) below, the syllogism in (13) is intuitively invalid: by substitution, the first two sentences appear to lead to the invalid conclusion in (13c).

\footnotetext{
6 For more detailed overviews of CQ-analyses in the literature see Nathan (2006) and Romero (2006).

7 The main difference among the aforementioned CQ-analyses is whether the crucial type-shift operation applies to the DP-CQ directly (question/proposition approaches) or whether it is incorporated in a designated lexical entry for the embedding predicate (property/individual concept approaches). Thanks to Kyle Rawlins for discussing this point with me.
} 
(12) a. The mayor of Northampton is Ms. Higgins.

b. The mayor of Northampton lives on Main St.

c. Ms. Higgins lives on Main St.

(13) a. The temperature in this room is ninety.

b. The temperature in this room is rising.

c. Ninety is rising.

Montague's account of the contrast between the valid argument in (12) and the (invalid) temperature paradox in (13) has three major components. ${ }^{8}$ First, definite descriptions like the mayor of Northampton and the temperature in this room do not denote individual entities, but rather individual concepts, i.e. functions from indices (world/time pairs) to entities. These functions, as opposed to the constant functions denoted by proper names like Ms. Higgins and ninety, can yield different values at different indices. Second, Montague assumes that equative be, as in The temperature is 90 or The mayor is Ms. Higgins, expresses extensional identity. Thus, as can be seen in (14a) and (15a) below, the first premise of both arguments does not assert that two ICs are identical, but rather that their extensions are the same at the index of evaluation. Finally, according to Montague, the significant difference between the valid argument in (12) and the temperature paradox lies in the kind of predication involved in the second premise. While in (14b) the extensional predicate lives on Main Street applies to the value of the function denoted by the mayor of Northampton (f) at the index of evaluation, in (15b) the (temporally) intensional predicate rise applies to the function denoted by the temperature in this room ( $\left.\mathbf{f}^{\prime}\right)$, not to its value. (Intuitively, in order to establish whether the temperature is rising, one needs to look not just at the actual temperature value, but also at the values that the function yields at earlier and later indices.)

(14) a. The mayor of Northampton is Ms Higgins.

$$
\mathbf{f}\left(\mathbf{i}_{\mathbf{0}}\right)=\mathbf{g}\left(\mathbf{i}_{\mathbf{0}}\right)
$$

extensional identity

b. The mayor of Northampton lives on Main

Street.
lives-on-MS $\mathbf{M S}_{\mathbf{i} 0}\left(\mathbf{f}\left(\mathbf{i}_{\mathbf{0}}\right)\right)$
c. Ms Higgins lives on Main Street. lives-on- $\mathbf{M S}_{\mathbf{i 0}}\left(\mathbf{g}\left(\mathbf{i}_{\mathbf{0}}\right)\right)$

(15) a. The temperature in this room is ninety.

$$
\mathbf{f}^{\prime}\left(\mathbf{i}_{\mathbf{0}}\right)=\mathbf{g}^{\prime}\left(\mathbf{i}_{\mathbf{0}}\right)
$$

extensional identity

b. The temperature in this room is rising.

$$
\text { rise }_{\mathbf{i} 0}\left(\mathbf{f}^{\prime}\right)
$$

intensional predication

c. Ninety is rising.

$$
\text { rise }_{\mathbf{i 0}}\left(\mathbf{g}^{\prime}\right)
$$

It is easy to see that from the truth of $(14 a, b)$ the truth of $(14 c)$ must follow. The same does not hold for (15). Given that the temperature function that yields 90 at $\mathbf{i}_{\mathbf{0}}$ can be different from the constant function that yields 90 at all indices, $(15 \mathrm{a}, \mathrm{b})$ can be true even if (15c) is false. Therefore, the paradox is resolved.

\footnotetext{
${ }^{8}$ What follows is a simplified version of Montague's original analysis. (Cf. Montague 1974, pp. 30-31.)
} 
In analogy to the temperature paradox, Heim (1979) proposes the following invalid argument involving CQ-readings of the DPs in italics.

(16) a. The capital of Italy is the largest town in Italy.

b. John knows the capital of Italy.

c. John knows the largest town in Italy.

(Heim 1979, p. 54)

The entailment in (16) does not go through if we assume that the DPs in italics are interpreted as CQs. Intuitively, knowing what the capital of Italy is does not entail knowing what the largest town in Italy is, despite the fact that the two DPs are coreferential at the actual world/time index. As Heim points out, the lack of entailment is expected if the CQs in (16) denote individual concepts and know can select for individual concepts. On a par with Montague's analysis of the temperature paradox, (16) can be analyzed as in (17) below.

(17) a. The capital of Italy is the largest town in Italy. $\mathbf{f}\left(\mathbf{i}_{\mathbf{0}}\right)=\mathbf{g}\left(\mathbf{i}_{\mathbf{0}}\right)$

extensional identity

b. John knows the capital of Italy.

know $_{\mathbf{i 0}}(\mathbf{f})(\mathbf{j o h n})$

c. John knows the largest town in Italy.

know $_{\text {i0 }}($ g)(john)

intensional predication

Setting aside the semantic interpretation of know for the moment, the failure of entailment can be explained by assuming that equating the value of two concepts at the actual index (17a) is not enough to guarantee identity across indices. Therefore, the conclusion in $(17 \mathrm{c})$ does not follow from the premises of the argument.

\subsection{Romero (2005): know $_{C Q-s e}$}

Building on Heim (1979), Romero (2005) develops a detailed analysis of CQs embedded under epistemic know. Romero's denotation for know as a predicate selecting for individual concepts is given in (18) below (where Dox $x_{x}(w)$ stands for the set of worlds compatible with what the attitude holder $x$ believes in world $w$, i.e. the set of $x^{\prime}$ s doxastic alternatives to $\left.w\right) .^{9,10}$

(18) $\llbracket k n o w_{\mathrm{CQ}-\mathrm{se}} \rrbracket^{\mathrm{w}}=\lambda f_{<\mathrm{s}, \mathrm{e}>} \lambda x_{\mathrm{e}} . \forall w^{\prime} \in \operatorname{Dox}_{x}(w)\left[f\left(w^{\prime}\right)=f(w)\right]$

\footnotetext{
9 Romero (2005) uses a notation with world variables in the metalanguage (2-sorted type theory). For consistency's sake, all the formulas from her paper are translated into the notation used in this paper.

${ }^{10}$ Romero emphasizes that an IC-based analysis of CQs with epistemic know is a parsimonious extension of the analysis assumed for question-embedding know, whose entry is given in (i).
}

(i) $\llbracket k n o w_{\mathrm{Q}} \rrbracket^{\mathrm{w}}=\lambda Q_{\ll \mathrm{s}, \mathrm{t}>, \mathrm{t}>} \lambda x_{\mathrm{e}} \cdot \forall w^{\prime} \in \operatorname{Dox}_{x}(w)\left[Q\left(w^{\prime}\right)=Q(w)\right]$

According to Romero, "the parallelism between Karttunen's question meaning and the individual concept in $\left[(19)\right.$, i.e. $\lambda \mathrm{w}^{\prime}$. 【the capital of Italy $\left.\rrbracket^{\mathrm{w}^{\prime}}\right]$ is obvious. A question maps a world to a possibly non-singleton set of propositions. For example, $\mathbb{\llbracket}\left[\left[_{C P}\right.\right.$ what is the capital of Italy $\rrbracket$ maps the actual world $\mathrm{w}$ to the singleton $\left\{\lambda w^{\prime}\right.$.capital-of(rome, italy, $\left.\left.w^{\prime}\right)\right\}$. An individual concept maps a world to a possibly nonsingular individual. For example, the individual concept contributed by [NP the capital of Italy] maps the actual world w to the singular individual Rome." (Romero 2005, p. 693) 
Although Romero does not explicitly argue in favor of any particular method of deriving the individual concept argument of $k n o w_{\mathrm{CQ}}$-se, one way to obtain such argument is via Intensional Functional Application (IFA), defined in (19) below.

(19) Intensional Functional Application (Heim and Kratzer 1998)

If $\alpha$ is a branching node and $\{\beta, \gamma\}$ the set of its daughters, then, for any possible world $\mathrm{w}$ and any assignment $\mathrm{a}$, if $\llbracket \beta \rrbracket^{\mathrm{w}, \mathrm{a}}$ is a function whose domain contains $\lambda \mathrm{w}^{\prime}$. $\llbracket \gamma \rrbracket^{\mathrm{w}^{\prime}, \mathrm{a}}$, then $\llbracket \alpha \rrbracket^{\mathrm{w}, \mathrm{a}}=\llbracket \beta \rrbracket^{\mathrm{w}, \mathrm{a}}\left(\lambda \mathrm{w}^{\prime} . \llbracket \gamma \rrbracket^{\mathrm{w}^{\prime}, \mathrm{a}}\right)$.

The truth conditions of a simple CQ-sentence like (20) can then be compositionally derived as shown in (21) below.

(20) John knows the capital of Italy.

$C Q$ : John knows what the capital of Italy is.

(21) a. 【the capital of Italy $\rrbracket^{\mathrm{w}, \mathrm{g}}=1 x_{\mathrm{e}}[x$ is capital of Italy in $w]$

b. $\llbracket J o h n$ knows the capital of Italy $\rrbracket^{\mathrm{w}, \mathrm{g}}=$

$=\llbracket$ know $_{\mathrm{CQ}-\mathrm{se}} \rrbracket^{\mathrm{w}, \mathrm{g}}\left(\lambda \mathrm{w}^{*}\right.$. $\llbracket$ the capital of Italy $\left.\rrbracket^{\mathrm{w}^{*}, \mathrm{~g}}\right)\left(\llbracket J o h n \rrbracket^{\mathrm{w}, \mathrm{g}}\right)$

$=\forall w^{\prime} \in \operatorname{Dox}_{\mathbf{J}}(w)\left[\left(\lambda \mathrm{w}^{*} \cdot \llbracket\right.\right.$ the capital of Italy $\left.\rrbracket^{\mathrm{w}^{*}, \mathrm{~g}}\left(\mathrm{w}^{\prime}\right)\right)=$ $\left(\lambda \mathrm{w}^{*} . \llbracket\right.$ the capital of Italy $\left.\left.\rrbracket^{\mathrm{w}^{*}, \mathrm{~g}}(\mathrm{w})\right)\right]$

$=\forall w^{\prime} \in \operatorname{Dox}_{\mathbf{J}}(w)\left[x_{\mathrm{e}}\left[x\right.\right.$ is capital of Italy in $\left.w^{\prime}\right]=$ $x_{\mathrm{e}}[x$ is capital of Italy in $\left.w]\right]$

According to the formula above, the sentence John knows the capital of Italy is true in the world of evaluation $w$ iff all of John's belief worlds $w^{\prime}$ are such that the unique individual that is the capital of Italy in those belief worlds is the unique individual that is the capital of Italy in the actual world (i.e., in each world compatible with John's beliefs in the actual world, the capital of Italy is Rome). These truth conditions correctly capture the intuitive interpretation of the sentence under its CQ-reading.

In the next section, I will move on to quantified CQ-objects. I will start by addressing quantified CQs with pair-list readings. Specifically, I am going to show that the IC-analysis just described can be extended to quantified CQs with functional nouns. I will only later return to set readings and pair-list readings with nonfunctional nouns and show how these cases will force us to make more substantial amendments to the original IC-approach.

\section{Quantified CQs and pair-list readings: functional nouns}

In this section, I propose an extension of Heim/Romero's IC-analysis that accounts for pair-list readings with functional nouns. The account presented here can be seen as a natural extension of Romero's (2005) analysis of definite CQs, enriched by observations from Nathan (2006) on the nature of predicates of individual concepts.

\subsection{Quantification over concepts}

In Sect. 2.2, I showed that definite CQs could be derived by combining an individual-denoting DP with Romero's entry for know ${ }_{\mathrm{CQ}}$ se by IFA. This simple 
machinery, however, won't work for examples with a quantified CQ-object, like (22).

(22) a. Mary knows every capital.

b. Pair-list reading: For every country $x$, Mary knows what the capital of $x$ is.

According to standard assumptions, a quantified DP does not denote an individual, nor could it denote the intension of an individual (i.e., an individual concept). Hence it cannot serve directly as the internal argument of know $w_{\mathrm{CQ}-\mathrm{se}}$. Type mismatches of this sort, however, are commonly resolved by raising the problematic quantificational phrase to a higher position (via Quantifier Raising, QR), leaving a trace of the appropriate semantic type in the starting position. In the case at hand, the trace left by QR-movement of the quantified DP must be of type $<$ s,e $>$ (i.e., the semantic type of a concept) in order to combine with know ${ }_{\mathrm{CQ}-\mathrm{se}}$, as (23) below shows.

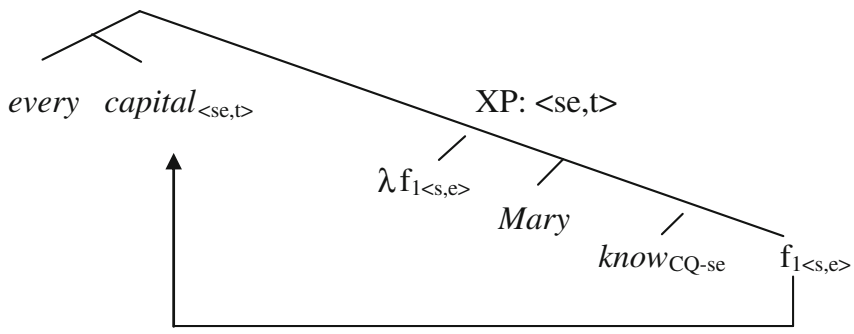

In (23), the quantificational determiner every must relate two sets of individual concepts: the set denoted by capital and the set denoted by $\lambda f_{1}$ Mary knows $f_{1}$. Thus, the pair-list reading of (22a) could be derived by quantifying over individual concepts corresponding to different capital-concepts, as shown in (24).

$$
\begin{aligned}
& \forall f_{<\mathrm{s}, \mathrm{e}}>\left(\text { capital }(f) \rightarrow \text { know }_{\mathrm{CQ}-\mathrm{se}}(f)(\text { mary })\right) \\
& \left(\text { For every } f_{<\mathrm{s}, \mathrm{e}}>\text { such that } f\right. \text { is a capital concept, Mary knows } \\
& \text { CQ-se } f \text {.) }
\end{aligned}
$$

Before moving on, let's take note of the fact that the analysis just sketched here requires the NP-CQ capital to denote a predicate of individual concepts (henceforth abbreviated as IC-predicate), an assumption that was not required in the case of definite CQs (recall that in order to derive CQ-readings for definite descriptions, the IC-argument of know $_{\mathrm{CQ} \text {-se }}$ was crafted by taking the intension of the individual denoted by the definite).

When combining the analysis sketched in (24) with Romero's entry for know ${ }_{\mathrm{CQ}-\mathrm{se}}$, we derive the following truth conditions for (22a):

$$
\begin{aligned}
& \llbracket \text { Mary knows every capital } \rrbracket^{\mathrm{g}, \mathrm{w}}= \\
& \forall f_{<\mathrm{se}>}\left(\text { capital }(f) \rightarrow \forall w^{\prime} \in \operatorname{Dox}_{M}(w)\left[f\left(w^{\prime}\right)=f(w)\right]\right)
\end{aligned}
$$

According to the formula in (25), checking for the truth of (22a) (under its pair-list reading) amounts to checking whether every capital concept in the set picked out by 
the IC-predicate capital yields the same value at the actual world $w$ and at Mary's belief worlds. Do these truth conditions match our understanding of (22a) under the pair-list reading? In other words, are the inferences in (26) guaranteed by the truth conditions in (25)?

(26) Desired inferences for the pair-list reading of (22a):

Mary knows that the capital of Italy is Rome, that the capital of France is

Paris, that the capital of Argentina is Buenos Aires, etc., for all existing capital-country combinations.

As we will see in the next section, the answer to this question heavily depends on how we define the denotation of the NP-CQ capital as an IC-predicate. Under this analysis, the set of inferences in (26) can be derived only if the set of concepts picked out by capital consists of meaningfully sorted capital concepts (i.e., concepts like the capital of Italy, the capital of France, etc.), as opposed to functions consisting of arbitrary mappings from worlds to capital cities. In the next section, I present a way of deriving the right domain of concepts by means of a special typeshifter: Nathan's IC-shifter (Nathan 2006).

\subsection{Nathan's IC-shifter}

The goal of this section is to find a type-shifter that would shift the standard denotation of a noun like capital — which we independently need for extensional contexts like (27)—into a predicate of meaningfully sorted concepts.

(27) This summer Julio visited a European capital/ the capital of Italy.

To show that this is not a trivial matter, consider first the following (wrong) attempt. Assume that (29) is uttered in the context provided in (28) below.

(28) Context 1: Suppose the world consisted of only two countries, Italy and France. Assume further that the capitals of these countries are Rome and Paris, respectively, and that Mary is aware of that.

(29) Mary knows every capital.

Pair-list reading: For every country $x$, Mary knows what the capital of $x$ is.

Intuitively, the pair-list reading of (29) is true in Context 1. Assuming that capital denotes the 1-place predicate in (30) below, we would end up with the toy model in (31) below for Context 1 . Under this model, the only existing capitals in the actual world $w$ and in Mary's belief worlds $w^{\prime}$ are Rome and Paris.

(30) $\llbracket$ capital $\rrbracket^{\mathrm{w}}=\lambda x_{\mathrm{e}} \cdot x$ is a capital in $w . \quad<\mathrm{e}, \mathrm{t}>$

(31) Toy model 1

$$
\begin{aligned}
& \llbracket \text { capital } \rrbracket^{\mathrm{w}}=\{\text { Rome, Paris }\} \\
& \llbracket \text { capital } \rrbracket^{\mathrm{w}^{\prime}}=\{\text { Rome, Paris }\}
\end{aligned}
$$


Returning to our initial hypothesis: the pair-list reading of (29) should result by quantifying over the concepts in the set denoted by capital, as shown in (25). However, in our model the extension of capital in a given world is a set of individuals, not a set of concepts. One way to fix this type-problem is to say that the lexicon contains a type-shifter that applies to 1-place predicates and returns ICpredicates. (33) below would do.

(32) Type-shift 1 (preliminary version; Nathan 2006, p. 92)

$\llbracket \operatorname{SHIFT}(\mathrm{P}) \rrbracket^{\mathrm{w}}=\lambda f_{<\mathrm{s}, \mathrm{e}}>. \forall w^{\prime}\left[\llbracket \mathrm{P} \rrbracket^{\mathrm{w}^{\prime}}\left(f\left(w^{\prime}\right)\right)\right] \quad$ where $\mathrm{P}$ is of type $<e, t>$

What (32) does is this. It takes a predicate $\mathrm{P}$ of type $<\mathrm{e}, \mathrm{t}>$ and forms a corresponding predicate $\mathrm{Q}$ of type $<<\mathrm{s}, \mathrm{e}>$,t $>$ that satisfies the following condition: each concept $f$ in $\mathrm{Q}$ is such that for every world $w^{\prime}$, the individual value of $f$ at $w^{\prime}$ has the property $\mathrm{P}$ at $w^{\prime}$. However, once we apply the type-shift in (32) to the denotation of capital in our toy model 1, things go wrong. As (33) below shows, the set of concepts generated in this way would contain the two concepts $\mathrm{c} 1$ and $\mathrm{c} 2$, which intuitively correspond to the concepts standing for the capital of France and the capital of Italy in Context 1, but also two extra functions $\mathrm{c} 3$ and $\mathrm{c} 4$, which in this particular model/scenario are nothing more than arbitrary functions mapping worlds into capitals.

$$
\begin{aligned}
& \llbracket \text { SHIFT(capital) } \rrbracket^{\mathrm{w}}=\lambda f_{<\mathrm{s}, \mathrm{e}>} . \forall \mathrm{w}^{*} .\left[\operatorname{capital}_{\mathrm{w}^{*}}\left(f\left(w^{*}\right)\right)\right] \\
& \left\{\left(\begin{array}{l}
\mathrm{w} \rightarrow \text { Paris } \\
\mathrm{w}^{\prime} \rightarrow \text { Paris } \\
\mathrm{c} \text { (France) }
\end{array}\right),\left(\begin{array}{l}
\mathrm{w} \rightarrow \text { Rome } \\
\mathrm{w}^{\prime} \rightarrow \text { Rome } \\
\mathrm{c} 2 \text { (Italy) }
\end{array}\right),\left(\begin{array}{l}
\mathrm{w} \rightarrow \text { Paris } \\
\mathrm{w}^{\prime} \rightarrow \text { Rome } \\
\mathrm{c} 3
\end{array}\right),\left(\begin{array}{l}
\mathrm{w} \rightarrow \text { Rome } \\
\mathrm{w}^{\prime} \rightarrow \text { Paris } \\
\mathrm{c} 4
\end{array}\right)\right\}
\end{aligned}
$$

Moreover, if the set picked out by (33) were our domain of quantification, (29) would come out false, contrary to intuitions. This is because it is not the case that for every capital concept $f$ in (33), the value of $f$ is the same at $\mathrm{w}$ and $\mathrm{w}^{\prime}$. Thus, the conclusion seems to be that c3 and c4 should not count as capital-concepts in this particular context.

Consider next (35) in the scenario provided in (34) below.

(34) Context 2: Suppose the world consisted of only two countries, Italy and France. Assume that the capitals of these countries are Rome and Paris, respectively. This time, though, Mary wrongly believes that Paris is the capital of Italy and Rome is the capital of France.

(35) Mary knows two capitals.

Pair-list reading: There are two countries $x$ and $y$, such that Mary knows what the capital of $x$ is and what the capital of $y$ is.

Intuitively, the pair-list reading of (35) is false in Context 2. However, if we were to assume that capital denotes the 1-place predicate in (30) above, we would have to represent the facts given in Context 2 by the very same toy model we had before, i.e. (31). As a consequence, when capital undergoes the type-shifter in (32), we would end 
up with the same set of concepts in our domain, i.e. (33). This time, though, the concepts that intuitively correspond to the capital of France and the capital of Italy in Context 2 are c 3 and c4, not $\mathrm{c} 1$ and $\mathrm{c} 2$. Moreover, if we included $\mathrm{c} 1$ and $\mathrm{c} 2$ into our domain of quantification, we would wrongly predict (35) to be true. This is because there are in fact two concepts (namely, $\mathrm{c} 1$ and c2) whose values are the same at $\mathrm{w}^{\prime}$ and w. The conclusion seems to be then that we are clearly doing something wrong here.

Based on a problematic case analogous to the two cases just presented, Nathan (2006) argues that the individual concepts picked out by the IC-predicate denotation of relational nouns must be individuated on the basis of the noun's internal argument. ${ }^{11}$ Thus, capital is specified in the lexicon not as the 1-place predicate in (30), but as the 2-place predicate in (36). This 2-place predicate can then be shifted into an IC-predicate via the type-shifter in (37) below. ${ }^{12}$

(36) $\llbracket$ capital $\rrbracket^{\mathrm{w}}=\lambda x_{\mathrm{e}} \cdot \lambda y_{\mathrm{e}} \cdot y$ is the capital of $x$ in $\mathrm{w} . \quad<\mathrm{e}<\mathrm{e}, \mathrm{t}>>$

(37) Nathan's IC-shifter (Nathan 2006)

$\llbracket \mathrm{IC}(\alpha) \rrbracket^{\mathrm{w}}=\lambda f_{<\mathrm{s}, \mathrm{e}>} \exists x_{\mathrm{e}} \forall w^{\prime} \llbracket \alpha \rrbracket^{\mathrm{w}^{\prime}}(x)\left(f\left(w^{\prime}\right)\right)$

Let's see how Nathan's IC-shifter picks out the right set of concepts for our CQ-sentences. Returning to Context 1, an application of Nathan's IC-type shifter to the relational denotation of capital in (38) below creates the right set of concepts, as shown in (39).

(38) Toy model $1^{\prime}$

$\llbracket$ capital $\rrbracket^{\mathrm{W}}=\{<\mathrm{IT}$, Rome $>,<\mathrm{FR}$, Paris $>\}$ actual world

$\llbracket$ capital $\rrbracket^{\mathrm{w}^{\prime}}=\{<\mathrm{IT}$, Rome $>,<\mathrm{FR}$, Paris $>\}$ Mary's doxastic alternatives

$$
\llbracket \mathrm{IC}(\text { capital }) \rrbracket^{\mathrm{w}}=\lambda f_{<\mathrm{s}, \mathrm{e}>} \exists x_{\mathrm{e}} \forall w^{\prime}\left[f\left(w^{\prime}\right) \text { is the capital of } x \text { at } w^{\prime}\right]
$$

$$
\left\{\begin{array}{c}
w \rightarrow \text { Paris } \\
w^{\prime} \rightarrow \text { Paris } \\
\mathrm{c} 1 \text { (France) }
\end{array}\right\}, \quad\left(\begin{array}{c}
w \rightarrow \text { Rome } \\
w^{\prime} \rightarrow \text { Rome } \\
\mathrm{c} 2 \text { (Italy) }
\end{array}\right\}
$$

Given (37), only functions that are individuated on the basis of the particular country they are "capitals of" will be in the set picked out by IC(capital). In this case, the two concepts $\mathrm{c} 3$ and $\mathrm{c} 4$ from (33) will not be part of the set of ICs picked out by IC(capital) in Toy model $1^{\prime}$. This is because neither of the two functions satisfies the condition imposed by (37), according to which for a function $f$ to be part of the set denoted by $I C$ (capital), there has to be an $x$ such that, at every index $w, f(w)$ is the capital of $x$ at $w$.

Let us move on to Context 2. The denotation of capital in this scenario is given in the toy model 2 in (40) below.

\footnotetext{
11 Nathan's original argument was based on quantification over concepts in temporally intensional contexts (as in Every governor changed). Here, I adapt Nathan's discussion to CQs, but the logic of the argument is basically the same.

12 The internal argument of the relational noun does not have to be an individual; it can also be a kind (e.g. the internal argument of price in John knows every price). Following Carlson (1977) this won't require any change with respect to semantic types, given that kinds are also of semantic type e.
} 
(40) Toy model 2

【capital $\rrbracket^{\mathrm{w}}=\{<\mathrm{IT}$, Rome $>,<\mathrm{FR}$, Paris $>\}$ actual world

$\llbracket$ capital $\rrbracket^{\mathrm{w}^{\prime}}=\{<\mathrm{IT}$, Paris $>,<\mathrm{FR}$, Rome $>\}$ Mary's doxastic alternatives

Applying Nathan's IC-shifter to the denotation of capital in (40) yields a different set of concepts, as shown in (41) below.

$$
\left\{\left(\begin{array}{c}
w \rightarrow \text { Rome } \\
w^{\prime} \rightarrow \text { Paris } \\
\mathrm{c} 1 \text { (Italy) }
\end{array}\right), \quad\left(\begin{array}{l}
w \rightarrow \text { Paris } \\
w^{\prime} \rightarrow \text { Rome } \\
\mathrm{c} 2 \text { (France) }
\end{array}\right\}\right.
$$

These functions correspond to concepts c3 and c4 in (33). If we assume (41) as our domain of quantification, the sentence in (35) is now correctly predicted to be false. This is because it is not the case that there exist two capital-concepts in our domain whose values are the same at the actual world w and at Mary's belief worlds $\mathrm{w}^{\prime}$ (as a matter of fact none of the concepts in our domain are).

\subsection{Deriving pair-list readings with functional nouns}

Once we have the right denotation for IC(capital), we can derive the pair-list reading of (22a), repeated in (42), compositionally. This is shown in (43) below.

(42) a. Mary knows every capital.

b. Pair-list reading: For every country $\mathrm{x}$, Mary knows what the capital of $\mathrm{x}$ is.

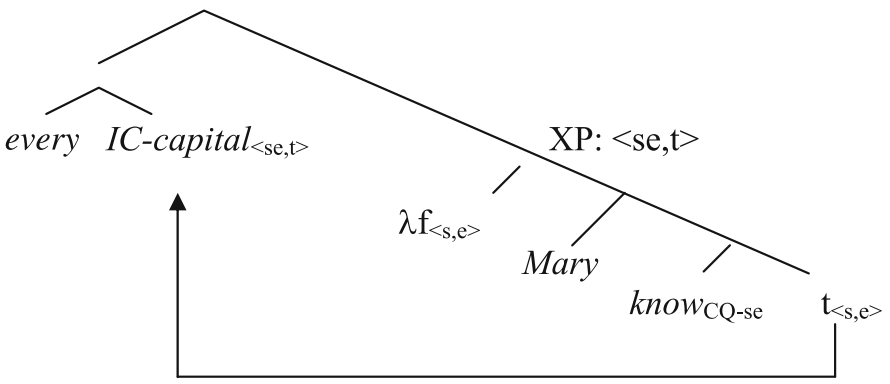

a. Lexical entries

1. $\left[\mathrm{IC}(\right.$ capital $) \rrbracket^{\mathrm{w}, \mathrm{g}}=\lambda, f_{<\mathrm{s}, \mathrm{e}>} \exists x_{\mathrm{e}} \forall w^{*}\left[f\left(w^{*}\right)\right.$ is the capital of $x$ at $\left.w^{*}\right]$

2. $\llbracket$ every $\rrbracket^{\mathrm{w}, \mathrm{g}}=\lambda P_{<<\mathrm{s}, \mathrm{e}>\mathrm{t}>} . \lambda Q_{<<\mathrm{s}, \mathrm{e}>\mathrm{t}>} . \forall f_{<s, e>}[P(f) \rightarrow Q(f)]$

3. $\llbracket k n o w_{\mathrm{CQ}-\mathrm{se}} \rrbracket^{\mathrm{w}, \mathrm{g}}=\lambda f_{<\mathrm{s}, \mathrm{e}>} \lambda x_{\mathrm{e}} \cdot \forall w^{\prime} \in \operatorname{Dox}_{x}(w)\left[f\left(w^{\prime}\right)=f(w)\right]$

4. $\llbracket$ Mary $\rrbracket^{\mathrm{w}, \mathrm{g}}=\mathrm{m}$

b. Truth conditions

$\llbracket$ Mary knows every capital $\rrbracket^{\mathrm{w}, \mathrm{g}}=$

$\forall f_{<\mathrm{s}, \mathrm{e}>}\left(\exists x_{\mathrm{e}} \forall w^{*}\left[f\left(w^{*}\right)\right.\right.$ is the capital of $x$ at $\left.w^{*}\right] \rightarrow \forall w^{\prime} \in \operatorname{Dox}_{m}(w)$

$\left.\left[f\left(w^{\prime}\right)=f(w)\right]\right)$ 
According to the formula above, the pair-list reading of the sentence Mary knows every capital is true in a world $\mathrm{w}$ iff every properly individuated capital concept yields the same value at $w$ and at Mary's belief worlds $w^{\prime}$.

Summing up, the account just presented derives pair-list readings by quantifying over a domain of meaningfully sorted concepts. Such domain is provided by the denotation of the NP-CQ after it undergoes Nathan's IC-shifter. Because of the way the shifter is defined, only concepts that are properly individuated (i.e., that are individuated on the basis of the relational noun's internal argument) will be included in the domain of quantification. Thus, checking for the truth of a quantified sentence like Mary knows every capital under its pair-list reading amounts to checking whether each (properly individuated) capital concept yields the same value at the actual world $w$ and at all the worlds according to Mary's beliefs in $\mathrm{w}$.

\subsection{A note on restrictive modification}

There are examples of pair-list readings in which a 2-place predicate NP-CQ is modified by an adjective or a prepositional phrase, as in $(44 a, b)$ below. As the paraphrases suggest, in these examples the modifier seems to contribute information about the internal argument of the relational noun.

(44) a. The cashier knows every price in the store.

$\mathrm{a}^{\prime}$. For every item (for sale) in the store, the cashier knows what its price is.

b. John knows every European capital.

$\mathrm{b}^{\prime}$. For every European country, John knows what its capital is.

As the paraphrases above show, when interpreting the sentences in (44a,b), we are confining our attention to individual concepts that are individuated on the basis of items sold in the store and of European countries. These intuitive paraphrases can be captured by having the modifier restricting the internal argument of the noun via the semantic mode of composition Restrict in (45) below (Chung and Ladusaw 2004).

(45) Restrict $\left(\llbracket \mathrm{R}_{<\mathrm{e},<\mathrm{e}, \mathrm{t}>>} \rrbracket^{\mathrm{w}, \mathrm{g}}, \llbracket \mathrm{P}_{<\mathrm{e}, \mathrm{t}>} \rrbracket^{\mathrm{w}, \mathrm{g}}\right)=\lambda x_{\mathrm{e} .} \lambda y_{\mathrm{e}} \cdot\left(\llbracket \mathrm{R} \rrbracket^{\mathrm{w}, \mathrm{g}}(x)(y) \&\right.$ $\left.\llbracket \mathrm{P} \rrbracket^{\mathrm{w}, \mathrm{g}}(x)\right)$

Similar examples were pointed out to me by an anonymous reviewer, who was concerned that the apparent saturation of the noun internal argument in examples like (46) below would lead to the (wrong) expectation that these sentences can only have set readings.

(46) a. Mary knows every capital of a European country.

b. Mike knows every phone number of a high-ranking administrator.

I suggest that the examples above could be treated in an analogous fashion as the examples in $(44 a, b)$, i.e. with the underlined material restricting — not saturatingthe internal argument of the noun, as shown in (47) below. 
(47) a. $\llbracket$ capital $\rrbracket^{\mathrm{w}, \mathrm{g}}=\lambda x_{\mathrm{e} .} \lambda y_{\mathrm{e}}[y$ is the capital of $x$ in $w]$

b. «European country $\rrbracket^{\mathrm{w}, \mathrm{g}}=\lambda x_{\mathrm{e}}[x$ is a country in the EU in $w]$

c. 【capital (of a) EU country $\rrbracket^{\mathrm{w}, \mathrm{g}}=\operatorname{Restrict}\left(\llbracket\right.$ capital $\rrbracket^{\mathrm{w}, \mathrm{g}}$, 【(of a) EU country $\rrbracket^{\mathrm{w}, \mathrm{g}}$ )

$=\lambda x_{\mathrm{e}} \lambda y_{\mathrm{e}}[y$ is the capital of $x$ at $w \& x$ is a country in the EU in $w]$

Given that the internal argument of the relational noun is restricted but not saturated, the NP-CQs in $(46 a, b)$ denote 2-place predicates. Hence, these examples are expected to have pair-list readings. ${ }^{13}$

\section{Back to the ambiguity: pair-list and set readings}

\subsection{Set readings and nonrelational NPs}

In the Introduction we saw that sentences with quantified CQ-objects, like (48) (repeated from (2)), are ambiguous between pair-list and set readings. We just saw how pair-list readings can be derived by quantifying over meaningfully sorted concepts. What about set readings? Can they also be derived by quantifying over concepts?

(48) Mary knows every capital.

Pair-list reading: For every country $x$, Mary knows what the capital of $x$ is.

Set reading: $\quad$ For every capital city $x$, Mary knows that $x$ is a capital.

Unfortunately, the account just provided for pair-list readings is not going to extend to set readings. As already observed, set readings correlate with 1-place predicate NPs. These can be NPs whose head noun is lexically nonrelational, like book in (49) (repeated from (5)), or relational nouns whose internal argument has been overtly saturated, such as member in (50) (repeated from (6)). In both cases, the semantic type of the NP-CQ is $<\mathrm{e}, \mathrm{t}>$ (1-place predicate) instead of $<\mathrm{e},<\mathrm{e}, \mathrm{t}>>$ (2-place predicate); therefore, Nathan's IC-shifter cannot even apply to derive a predicate of individual concepts. ${ }^{14}$

(49) Julio knows every book that Rita read this year.

Set reading: For every actual book that Rita read this year (Anna Karenina, Pride and Prejudice, etc.), Julio knows that it is $a$ book that Rita read this year.

\footnotetext{
13 The analysis sketched here only derives a narrow scope reading of the embedded indefinite (in fact, the indefinite is vacuous in this analysis). A sentence like (46b) also has an inverse linking reading (in the sense of May 1977), where the indefinite has wide scope. I leave the issue of how to derive inverse linking readings open for future research.

14 Nathan (2006) argues that when a nonrelational noun is modified by a relative clause (RC), as in (49), a CQ-reading is available because the RC itself acts as a shifter (more precisely, he postulates a special lexical entry for RCs that combine with nonrelational NP-CQs, where such denotation is created by a type-shifter operator). See Nathan (2006, pp. 117-120) for details on this proposal.
} 
(50) Bob knows every member of the Italian soccer team.

Set reading: For every actual member $x$ of the Italian soccer team (Buffon, Cannavaro, etc.), Bob knows that $x$ is $a$ member of the Italian soccer team.

Given the correlation between 1-place predicates and set readings, I suggest that the set reading of an ambiguous sentence like (48) is derived by assuming that the relational noun is used intransitively.

It is well known (cf. Barker 1995; Partee 1983/1997, a.o.) that relational nouns, like transitive verbs, do not necessarily require their internal argument to be overtly expressed. In the same way, one could leave the object of the verb ate unexpressed in (51), and there is no need to specify the internal argument of the relational noun enemy in (52).

(51) John ate.

(52) The enemy left.

The assumption commonly made in the literature is that relational nouns are listed in the lexicon as transitive predicates, whereas the intransitive entry is derived by means of a type-shifter (cf. Barker 1995; Nathan 2006, a.o.). Following the literature on verbal argument deletion, I will adopt the term indefinite object deletion (IOD) to refer to the use of a 2-place predicate without an overtly expressed internal argument. IOD can be implemented in the grammar through a type-shifter whose semantic effect amounts to existential closure of the noun's internal argument. (53) below would do (here $\alpha$ stands for a 2-place predicate: type $<\mathrm{e},<\mathrm{e}, \mathrm{t}\rangle>)$.

(53) Indefinite object deletion (IOD)

$\llbracket \operatorname{IOD}(\alpha) \rrbracket^{\mathrm{w}, \mathrm{g}}=\lambda x_{\mathrm{e}} \cdot \exists y_{\mathrm{e}} \cdot \llbracket \alpha \rrbracket^{\mathrm{w}, \mathrm{g}}(y)(x)$

Given the possibility of IOD, relational nouns are systematically ambiguous between transitive and intransitive meanings, as shown in $(54 a, b)$.

(54) a. $\llbracket$ capital $^{\mathrm{w}, \mathrm{g}}=\lambda z_{e} \cdot \lambda x_{e}$. [x is the capital of $z$ at $\left.w\right] \quad<\mathrm{e},<\mathrm{e}, \mathrm{t}>>$

b. $\llbracket I O D\left(\right.$ capital) $\rrbracket^{\mathrm{w}, \mathrm{g}}=\lambda x_{e} . \exists y_{\mathrm{e}}[x$ is the capital of $y$ at $w]<\mathrm{e}, \mathrm{t}>$

This, I argue, is the reason why sentences like (48) are ambiguous between pair-list readings and set readings. Pair-list readings derive from the relational meaning of the noun. The IC-approach derives this type of reading by quantifying over meaningfully sorted ICs (via Nathan's IC-shifter). On the other hand, when the relational noun is used intransitively, it is expected to pattern with nonrelational nouns and generate set readings, which remains to be accounted for. Summing up, the IC-approach does not obviously extend to quantified CQs with 1-place predicate NPs as classified in (55). 
(55) 1-place predicate NPs

a. NPs whose head noun is not relational (lexical 1-place predicates)

b. NPs whose head noun is relational with an overtly saturated internal argument

c. NPs whose head noun is relational with a covertly saturated internal argument (via IOD)

\subsection{Set readings with indefinite CQs}

Elsewhere, I pointed out that indefinite CQs are problematic for the IC-approach. Consider the examples from Frana (2006) in (56) below.

(56) a. John knows a doctor that can treat your illness.

b. Ram knows a shortcut to UMass.

Frana (2006) characterizes the problem as follows:
"When considering indefinites, however, the parallel with individual concepts becomes much weaker. It is clear that [(56a)], for example, is compatible with a scenario in which there are several doctors that can treat your illness. All we need for [(56a)] to be true is that John knows one of them. Thus, the meaning of a doctor that can treat your illness cannot be described as having an individual concept denotation, i.e. as a function from points of reference into single individuals - since at the same point of reference there might be more than one individual that satisfies the description."

It seems to me now that the problem presented by the sentences in (56) is not due to the fact that these DPs are indefinites (as opposed to definites), but rather to the fact that the NP-CQ is a 1-place predicate, hence incompatible with Nathan's IC-shifter. As a matter of fact, treating indefinite CQs like other quantified phrases (i.e., by assuming QRmovement) is a viable option when the head noun of the CQ is relational. Consider (56) below, for instance. Assuming Nathan's IC-shifter applies to the denotation of the 2-place predicate price, QR-movement delivers the interpretable structure in (57b), where a trace of type $<\mathrm{s}$,e $>$ is in the argument position of know $\mathrm{CQ}$-se.

(57) a. Mary knows a price (in the store).

b. $\exists \mathrm{f}_{<\mathrm{s}, \mathrm{e}}>\left(\llbracket \mathrm{IC}(\right.$ price $) \rrbracket^{\mathrm{w}, \mathrm{g}}$ (f) \& $\llbracket k n o w_{\mathrm{CQ}-\mathrm{se}} \rrbracket^{\mathrm{w}, \mathrm{g}}(\mathrm{f})($ mary $\left.)\right)$

The problem with the examples in (56) is due to the fact that the head nouns of the CQs are not relational. What kind of individual concepts could be in the set picked out by doctor who can treat your illness? Clearly not functions that map an index $w$ to the unique individual that is a doctor who can treat your illness at $w$, given that at the same index there may be more than one doctor who can treat your illness. Thus, indefinite CQs with 1-place predicate NPs incur the same problem discussed with respect to quantified CQs with this type of NP, namely the impossibility of shifting certain NPs into IC-predicates. 


\section{Toward an account of set readings}

In this section, I argue that the challenge presented by set readings is the direct consequence of certain assumptions we have made about the interpretation of traces, i.e. that traces are semantically impoverished objects. Under this view, a trace is nothing more than a bound variable, whose semantic contribution-in cases in which the NP-CQ is a 1-place predicate-is rigid. Hence, it cannot be a suitable argument for an intensional predicate like $k n o w_{\mathrm{CQ}-\mathrm{se}}$. Let's see why this is the case. Under the assumption that set readings always correlate with 1-place predicate NPs (semantic type $<\mathrm{e}, \mathrm{t}>$ ), a possible LF for (58a), is given in (58b) below (here QR has raised the CQ to a position above $k n o w_{\mathrm{CQ}-\mathrm{se}}$ ).

(58) a. Mary knows every capital.

b. LF: every IOD (capital) $\lambda x_{1}$. Mary knows ${ }_{\mathrm{CQ}-\mathrm{se}} x_{1} \quad$ (set reading)

A trace of type $e$ is not, however, the right kind of argument for know $w_{\mathrm{CQ}-\mathrm{se}}$. An application of IFA would rescue the type mismatch, but the truth conditions derived in this way would be trivially fulfilled, as (59) shows. This is because the intensional object generated by IFA would be a constant function mapping possible worlds to the value assumed by the bound variable $x_{1}$. Thus, the value of such function at the actual world and at Mary's belief worlds would necessarily be the same, causing the whole sentence to be trivially true.

$$
\begin{aligned}
& \llbracket \text { Mary knows every } \operatorname{IOD}(\text { capital }) \rrbracket^{\mathrm{w}, \mathrm{g}}= \\
& \forall x\left(\exists y_{\mathrm{e}}[x \text { is the capital of } y \text { at } w] \rightarrow\right. \\
& \left.\forall w^{\prime} \in \operatorname{Dox}_{\mathrm{m}}(w)\left[\left(\lambda \mathrm{w}_{2} \cdot \llbracket x_{1} \rrbracket^{\mathrm{w}_{2}, \mathrm{~g}[1 / \mathrm{x}]}\right)\left(w^{\prime}\right)=\left(\lambda \mathrm{w}_{3} \cdot \llbracket x_{1} \rrbracket^{\mathrm{w}_{3}, \mathrm{~g}[1 / \mathrm{x}]}\right)(w)\right]\right) \\
& \equiv \forall x\left(\exists y_{\mathrm{e}}[x \text { is the capital of } y \text { at } w] \rightarrow\right. \\
& \left.\forall w^{\prime} \in \operatorname{Dox}_{\mathrm{m}}(w)\left[\llbracket x_{1} \rrbracket^{\mathrm{w}^{\prime}, \mathrm{g}[1 / \mathrm{x}]}=\llbracket x_{1} \rrbracket^{\mathrm{w}, \mathrm{g}[1 / \mathrm{x}]}\right]\right)
\end{aligned}
$$

In the next sections I am going to show how the problem described above vanishes once we adopt an independently motivated view of traces, namely that traces are copies with semantic content. Following Fox $(1999,2002)$, traces of ordinary quantified DPs are definites of type $e$, which are, in a certain sense, non-rigid: they don't have an extension in every possible world. This feature will be crucial to avoid trivial meanings in combination with know $_{\mathrm{CQ} \text {-se }}$. In the coming two sections, I will start by briefly laying out independent assumptions that motivate Fox's copy theory of traces.

\subsection{The copy theory of movement}

It is well known that in certain environments a moved quantifier phrase or whphrase acts as though it is present in its base position for the purposes of binding conditions, like Condition $\mathrm{C}$ of the binding theory. In (60), for example, the referring expression John cannot be co-valued with the pronoun he, even though at surface structure John is not c-commanded by the pronoun he.

(60) * Which picture of $\mathrm{John}_{\mathrm{i}}$ does he $\mathrm{i}_{\mathrm{i}}$ like? 
Thus, even though wh-movement removes the name John from the c-command domain of the pronoun he, the result is ungrammatical in the same way that the following example without movement is:

* $\mathrm{He}_{\mathrm{i}}$ likes which picture of $\mathrm{John}_{\mathrm{i}}$ ?

In (61), the referring expression John is c-commanded by the co-indexed pronoun, resulting in a violation of Principle $\mathrm{C}$ of the binding theory (and, hence, yielding ungrammaticality). Since in (60) John cannot be co-referential with the pronoun he, it is often assumed that the moved phrase is subject to the same binding conditions as if it were in its base position. Similarly in (62), although QR can move the universally quantified DP every friend of John's outside the c-command domain of the pronoun him, the two expressions cannot be interpreted as co-referential.

(62) ??/* Someone introduced him ${ }_{\mathrm{i}}$ to every friend of $\mathrm{John}_{\mathrm{i}}$ 's. (Fox 2002, p. 64)

LF: [every friend of $\left.\mathrm{John}_{\mathrm{i}}{ }^{\prime} \mathrm{s}\right]_{\mathrm{j}}$ someone introduced $\operatorname{him}_{\mathrm{i}}$ to $\mathrm{t}_{\mathrm{j}}$

The morale from these examples is that neither wh-movement nor QR can reverse the verdict of Condition $\mathrm{C}$; the moved phrases behave syntactically (and semantically) as if they were in their base position. Such effects are known as reconstruction effects.

A prominent recent account of reconstruction effects is the copy theory of movement (Chomsky 1995). Under the copy theory of movement, movement operations create a chain of identical copies of the moved constituent. For instance, to form the question in (60), wh-movement of which picture of John will get the representation in (63).

(63) $*$ [which picture of $\mathrm{John}_{\mathrm{i}}$ ] does he $\mathrm{i}_{\mathrm{i}}$ like [which picture of $\left.\mathrm{John}_{\mathrm{i}}\right]$ ?

As (63) shows, the gap of the moved phrase is occupied by a copy of the moved expression, which must be subject to the same requirements that overt phrases are (in this case, the fact that the referential expression John in the copy trace is c-commanded by a co-indexed pronoun constitutes a violation of Principle $\mathrm{C}$ of the binding theory). Similarly, in the case of (62), the copy theory of movement will assign to the sentence the LF in (64), in which a copy, instead of an impoverished trace, is present at the tail of the movement chain. Given that copy traces are subject to the same requirements that overt phrases are, the sentence is predicted to be ungrammatical because of a Principle $\mathrm{C}$ violation (the referential expression John in the copy trace is c-commanded by a co-indexed pronoun).

(64) * [every friend of $\mathrm{John}_{\mathrm{i}}$ 's] someone introduced him $\mathrm{i}_{\mathrm{i}}$ to [every friend of $\mathrm{John}_{\mathrm{i}}$ 's]

To conclude, one of the arguments in favor of the copy theory of movement is based on the observation that movement does not obviate a violation of Condition $\mathrm{C}$. This fact is mysterious if traces are impoverished objects, but it is expected under the copy theory of movement, which postulates structures like (63) and (64), where 
copies are subject to the same syntactic restrictions that overt phrases are. I will now address the question of how copies are interpreted.

\subsection{The interpretation of copy traces (Fox 1999, 2002)}

What are the consequences, for semantic theory, of adopting the copy theory of movement? Under a QR-based analysis (cf. May 1977; Heim and Kratzer 1998, a.o.), the meaning of a sentence involving a quantified phrase in object position, like (65a) below, is derived by QR-movement of the quantified DP to a higher position. By effect of such movement a $\lambda$-binder is introduced at LF, which binds the trace left by the moved phrase. The resulting property $\lambda x_{\mathrm{i}}$. the teacher talked to $x_{\mathrm{i}}$ is then combined with the denotation of the QP every student by Functional Application.

(65) a. Sue talked to every student.

b. [every student] $\lambda \mathrm{x}_{\mathrm{i}}$. Sue talked to $\mathrm{x}_{\mathrm{i}}$

In principle, lower copies could also be treated as bound variables. If that were the case, the copy theory of movement would not introduce any modification with respect to semantic interpretation. However, according to Fox, the adoption of the copy theory of movement opens other possibilities. Specifically, "if operator variable constructions are to be formed, the copy at the tail of the chain can be converted to an element that contains a variable in various ways" (Fox 2002, p. 66). Fox's suggestion is that the copy at the tail of the chain is converted to a definite description containing a bound variable, yielding an interpretation similar to the paraphrase in (66b).

(66) a. [every student] Sue talked to [every student]

b. For every student $x_{i}$, Sue talked to the student $\mathbf{x}_{\mathbf{i}}$. (Fox 2002, p. 66)

According to Fox (2002), the definite description the student $x$ in the paraphrase is modeled after actual definite descriptions such as the man John. These definite descriptions are interpreted by combining (via Predicate Modification, PM) the meaning of the first predicate ( $m a n$ ) with the identity predicate $\lambda y . y=J o h n$, with the resulting predicate serving as the argument of the determiner. Similarly, the meaning of the copy the student $x_{i}$ in $(66 \mathrm{~b})$ can be derived by combining (via PM) the meaning of student with the identity predicate $\lambda y . y=x_{i}$, with the resulting predicate serving as an argument of the determiner.

However, how do we get from the copy every student in (66a) to a definite description containing a bound variable (the student $x_{i}$ )? First of all, Fox assumes that movement of a phrase triggers the introduction of a $\lambda$-binder, co-indexed with the copy of the QP. As a result, the structure assigned to the example in (65a) would be $(67):{ }^{15}$

\footnotetext{
15 Here I assume, following Sauerland (2004), that the index is just on the determiner inside the copy trace.
} 
(67) [every student] $\lambda x_{i}$. Sue talked to [every ${ }_{i}$ student]

Second, the copy trace is converted into a definite description by an operation dubbed trace conversion, which consists of two sub-operations: variable insertion and determiner replacement. ${ }^{16}$

(68) Trace conversion (Fox 2002)

a. Variable insertion: $\left(\right.$ Det $\left._{\mathrm{n}}\right)$ Pred $\rightarrow\left(\right.$ Det $\left._{\mathrm{n}}\right)$ [Pred $\left.\lambda y\left(y=x_{n}\right)\right]$

b. Determiner replacement: $\left(\operatorname{Det}_{\mathrm{n}}\right)\left[\right.$ Pred $\left.\lambda y\left(y=x_{n}\right)\right] \rightarrow$ the [Pred $\left.\lambda y\left(y=x_{n}\right)\right]$

After trace conversion, (65a) is analyzed as in (69) below, where the student $x_{i}$ is shorthand for the ( $\lambda y . y$ is a student \& $y=x_{i}$ ).

(69) [every student] $\lambda x_{i}$ Sue talked to [the student $x_{i}$ ]

Assuming that the definite operator inserted by trace conversion is the standard presuppositional definite article, whose entry is given in (70) below, a descriptive trace gets interpreted as shown in (71) below.

(70) $\llbracket$ the $\rrbracket^{\mathrm{w}, \mathrm{g}}=\lambda \mathrm{P}_{<\mathrm{e}, \mathrm{t}>}: \exists ! x \mathrm{P}(x) . \imath x \cdot \mathrm{P}(x)$

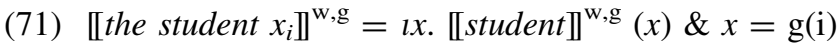
if $\exists ! x \llbracket$ student $\rrbracket^{\mathrm{w}, \mathrm{g}}(x) \& x=\mathrm{g}(\mathrm{i})$, otherwise undefined.

Given that (71) basically reduces to (72), we can conclude that a descriptive trace is interpreted like a pronoun (or a nondescriptive trace) - in the sense that its value is provided by the variable assignment function - but with the presupposition that this value is in the extension of the predicate NP at the world of evaluation.

(72) $\llbracket$ the student $x_{i} \rrbracket^{\mathrm{w}, \mathrm{g}}=\mathrm{g}(i)$ if $\llbracket$ student $\rrbracket^{\mathrm{w}, \mathrm{g}}(\mathrm{g}(i))$, otherwise undefined.

At this point, one can easily verify that the truth conditions of (65a) derived under the standard QR-based analysis in (65b) are equivalent to those derived assuming the copy theory of movement and Fox's trace conversion mechanism. (In fact, the LF in (69) is interpreted in the following way: (given an arbitrary world $w$ ) for every $x$, if $x$ is a student in $w$ then Sue talked to the student $x$ in $w$.) In the next section, I am going to show how Fox's descriptive traces can be employed in the derivation of set readings.

\footnotetext{
${ }^{16}$ Fox (2002) suggests a possible way in which trace conversion could be reduced to a single operation: "Irene Heim (p.c.) points out that the definite article is the only determiner that can appear in natural language in the environment _ _ NP $a$ where $a$ denotes an element of type e. This observation, she suggests, might make it possible to derive Determiner Replacement as a necessary consequence of Variable Insertion" (Fox 2002, fn. 6).
} 


\subsection{Deriving set readings}

We have established that a copy trace is interpreted as shown in (73) below. From (73), we can also derive (74), which we will need when looking at intensional contexts.

(73) Copy trace interpretation:

$\llbracket$ the Pred $x_{i} \rrbracket^{\mathrm{w}, \mathrm{g}}=\mathrm{g}(i)$ if $\llbracket$ Pred $\rrbracket^{\mathrm{w}, \mathrm{g}}(\mathrm{g}(i))$, otherwise undefined.

(74) Identity of copy traces across worlds (preliminary version):

Given two arbitrary worlds $w$ and $w^{\prime}$, $\llbracket$ the Pred $x_{i} \rrbracket^{\mathrm{w}, \mathrm{g}}=$ $\llbracket$ the Pred $x_{i} \rrbracket^{\mathrm{w}^{\prime}, \mathrm{g}}$ if $\llbracket$ Pred $\rrbracket^{\mathrm{w}}(\mathrm{g}(\mathrm{i}))=1 \& \llbracket$ Pred $\rrbracket^{\mathrm{w}^{\prime}}(\mathrm{g}(\mathrm{i}))=1$, otherwise $\llbracket$ the Pred $x_{i} \rrbracket^{\mathrm{w}, \mathrm{g}}=\llbracket$ the Pred $x_{i} \rrbracket^{\mathrm{w}^{\prime}, \mathrm{g}}$ is undefined.

Let's now see how copy traces can help us derive set readings. Consider (75) in the context provided below, which makes the set reading salient.

Suppose, John's task is to assign to a new phone a number that is not yet taken by any other phone [in this office]. Then he needs to know every phone number not in the sense of knowing which number is whose, but merely in the sense of knowing which numbers are somebody's at all.

(Heim 1979)

(75) John knows every phone number (in this office).

Set reading: For every actual telephone number in this office (413-678, 413-254, etc.), John knows that it is somebody's telephone number.

Under the copy theory of movement, (75) has the LF in (76a) below (recall that we are assuming IOD in cases where a relational noun is interpreted intransitively).

(76) a. [every IOD (phone\#)] John knows ${ }_{\mathrm{CQ} \text {-se }}$ [every IOD (phone\#)]

b. [every IOD (phone\#)] $\lambda x_{1}$ John knows $_{\mathrm{CQ} \text {-se }}$ [the IOD (phone\#) $x_{1}$ ]

After trace conversion, the copy at the tail of the chain is converted into the definite description the IOD(phone\#) $x_{1}$, whose denotation is given in (77) below.

(77) Descriptive trace (after trace conversion):

【the IOD (phone\#) $x_{1} \rrbracket^{\mathrm{w}, \mathrm{g}}=\mathrm{g}(1)$ if $\mathrm{g}(1)$ is a phone number in $w$, otherwise undefined.

Since the denotation of the descriptive trace is an entity of semantic type $e$, in order to combine it with know $_{\mathrm{CQ} \text {-se }}$ we would have to employ IFA. This time, though, the kind of individual concept generated is a partial constant function, i.e. a function that is defined only for those worlds in which the trace picks out a phone number. This suffices to avoid trivial truth conditions. The compositional derivation of the truth conditions of $(75)$ is shown in $(78 a, b)$ below. 
(78) a.

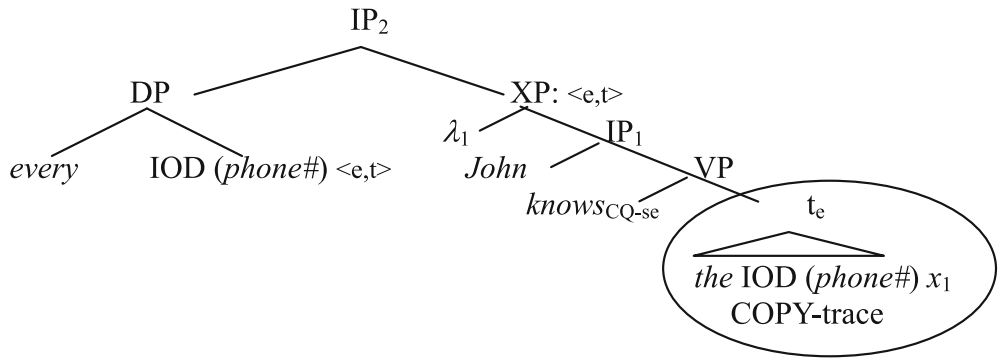

b. For any constituent $\alpha$ and variable assignment $g$,

$\llbracket \lambda_{\mathrm{iT}} \alpha \rrbracket^{\mathrm{w}, \mathrm{g}}=\lambda x_{\mathrm{T}} . \llbracket \alpha \rrbracket^{\mathrm{w}, \mathrm{g}[\mathrm{i} / \mathrm{x}]}$

c. $\llbracket$ John knows every IOD (phone \#) $\rrbracket^{\mathrm{w}, \mathrm{g}}=$

$\forall x_{e}\left(\exists u_{\mathrm{e}}\right.$ [phone\# $(u)(x)$ in $\left.w\right] \rightarrow \forall w^{\prime} \in \operatorname{Dox}_{\mathrm{J}}(w)$

([the IOD (phone\#) $x_{1} \rrbracket^{\mathrm{w}^{\prime}, \mathrm{g}[1 / \mathrm{x}]}=\llbracket$ the $\operatorname{IOD}\left(\right.$ phone\#) $\left.x_{1} \rrbracket^{\mathrm{w}, \mathrm{g}[1 / \mathrm{x}]}\right)$ )

Now, assume that (75) is uttered in a scenario in which it is true that for every actual phone number $x$, John knows that $x$ is a phone number. In this scenario, the formula in (78c) is true. In fact, in this scenario, (78c) is equivalent to (79) below.

$$
\left.\forall x_{e}\left(\exists u_{\mathrm{e}} \text { [phone\# }(u)(x) \text { in } w\right] \rightarrow \forall w^{\prime} \in \operatorname{Dox}_{j}(w)\left(\exists z_{\mathrm{e}}\left[\operatorname{phone} \#(z)(x) \text { at } w^{\prime}\right]\right)\right)
$$

According to (79), the sentence John knows every phone number is true (under its set reading) if and only if for every $x$ that is actually somebody's phone number, John believes that $x$ is somebody's phone number. These are the intuitive truth conditions of the sentence under the set reading.

Unfortunately though, as the careful reader may have spotted, this analysis of set readings is not quite correct yet. As a matter of fact, correct results follow only in case John knows what the right phone numbers are, as in the given scenario. Suppose, instead, that John is not right about which numbers are phone numbers in this office. In fact, he happens to have them all wrong. Intuitively, (75) is false in this scenario. However, given the truth conditions in $(78 \mathrm{c})$, the principle stated in (74), and the fact that John is not right about any of the existing phone numbers, we predict the sentence to lack a truth value. This is because, given the facts, the descriptive trace on the left side of the equation in (78c) would be undefined under any possible value of $x$ (because for every phone number $x$, John does not know that $x$ is a phone number, hence the denotation of the copy trace is undefined in his belief worlds). Thus, we predict that the sentence lacks a truth value, instead of being false. What we need instead of (74) is (80) below.

(80) Identity of copy traces across worlds (final version):

Given two arbitrary worlds $w$ and $w^{\prime}$,

$\llbracket$ the Pred $x_{i} \rrbracket^{\mathrm{w}, \mathrm{g}}=\llbracket$ the Pred $x_{i} \rrbracket^{\mathrm{w}^{\prime}, \mathrm{g}}$ iff $\llbracket$ Pred $\rrbracket^{\mathrm{w}, \mathrm{g}}(\mathrm{g}(\mathrm{i}))=\llbracket$ Pred $\rrbracket^{\mathrm{w}, \mathrm{g}}(\mathrm{g}(\mathrm{i}))$

Clearly, this problematic result is the direct consequence of the presupposition introduced by the definite article during trace conversion. Two potential solutions present themselves. We might either resort to local accommodation of the 
presupposition or, in intensional contexts, employ a definite operator that does not carry a presupposition of existence. In what follows, I will explore this second possibility. More precisely, I propose to remedy the problem by inserting a maximality operator during trace conversion, instead of the presuppositional definite article used by Fox. ${ }^{17}$

\subsection{Copy traces in intensional contexts and $\max$}

Correct results obtain if we assume that the definite operator inserted by trace conversion is the max operator defined in (81) below. This operator is a standard maximality operator (cf. Rullmann 1995, for example), with an additional clause designed to deal with empty sets. ${ }^{18}$

(81) For any set A (i.e. the extension of a predicate NP in $w$ ),

(i) if $\mathrm{A} \neq \varnothing$ then, $\max (\mathrm{A})=x\left[x \in \mathrm{A} \wedge \forall x^{\prime} \in \mathrm{A}\left[x^{\prime} \leq x\right]\right]$

(ii) if $\mathrm{A}=\varnothing$ then, $\max (\mathrm{A})=*$ (the null individual, which is not in any natural language denotation)

According to clause (i) of the above definition, when max applies to the extension of a predicate in a given world (a set), it returns the maximal element of that set (an individual when the set is a singleton set, or an individual sum when the set consists of more than one individual). The clause in (ii) says that if the set picked out by the predicate is empty, then $\max (\mathrm{A})$ returns the null individual. This last clause is going to solve our problem. Let's also assume the modified trace conversion mechanism in (82), which is identical to Fox's except that during determiner replacement, max is inserted, instead of the.

(82) Modified trace conversion

a. Variable insertion: $\left(\operatorname{Det}_{\mathrm{n}}\right)$ Pred $\rightarrow\left(\operatorname{Det}_{\mathrm{n}}\right)$ [Pred $\lambda y\left(y=x_{n}\right)$ ]

b. Determiner replacement: $\left(\operatorname{Det}_{\mathrm{n}}\right)\left[\right.$ Pred $\left.\lambda y\left(y=x_{n}\right)\right] \rightarrow$ $\max \left[\right.$ Pred $\left.\lambda y\left(y=x_{n}\right)\right]$

As (82) shows, after variable insertion, max combines with the predicate $\lambda y$. $\operatorname{Pred}(y) \& y=x_{1}$ whose extension in any given world $w$ can be either the singleton set containing the value assumed by the variable $x$ under a given assignment (when $x$ is Pred at $w$ ) or the empty set (when $x$ is not Pred at $w$ ). From the way max is defined, it follows that when it applies to a singleton set it returns the single (maximal) element of that set, and when it applies to the empty set, it returns the null individual. This amounts to (83). On the basis of (83), the equation

\footnotetext{
${ }^{17}$ Note that a Russellian entry for the definite article would not work for our purposes. This is because the definite description generated in this way would be a generalized quantifier, which cannot serve as the direct object of the verb.

18 The proposed solution implies the existence of strange objects in $\mathrm{D}_{\mathrm{e}}$ usually referred to as null or absurd individuals. Such objects have been previously employed in the literature on choice functions to resolve the 'empty NP-restrictor' problem (cf. von Stechow 1996; Reinhart 1997; Winter 1997). My proposal is close to von Stechow's (1996) analysis.
} 
' $\llbracket \max$ Pred $\mathrm{x}_{\mathrm{i}} \rrbracket^{\mathrm{w}, \mathrm{g}}=\llbracket \max$ Pred $\mathrm{x}_{\mathrm{i}} \rrbracket^{\mathrm{w}^{\prime}, \mathrm{g} \text { ' }}$ can be false, unlike ' $\llbracket$ the Pred $\mathrm{x}_{\mathrm{i}} \rrbracket^{\mathrm{w}, \mathrm{g}}=\llbracket$ the Pred $\mathrm{x}_{\mathrm{i}} \rrbracket^{\mathrm{w}^{\prime}, \mathrm{g}}, 19$

(83) Copy trace interpretation (with max)

$\llbracket$ max Pred $x_{i} \rrbracket^{\mathrm{w}, \mathrm{g}}=\mathrm{g}(i)$ if $\llbracket$ Pred $\rrbracket^{\mathrm{w}, \mathrm{g}}(\mathrm{g}(i))$, otherwise $\llbracket$ max Pred $x_{i} \rrbracket^{\mathrm{w}, \mathrm{g}}=*$

Now consider again the sentence John knows every phone number, which gets analyzed as shown in (84a) below (in the formula below, read phone\# as IOD(phone\#)). Assume next that the trace conversion mechanism in (82) converts the lower copy into the descriptive trace max phone\# $x_{1}$.

(84) a. [every phone\#] $\lambda x_{1}$. John knows [every $y_{i}$ phone\#]

b. [every phone\#] $\lambda x_{1}$. John knows [ $\max$ phone\# $\left.x_{1}\right]$

Now consider the truth conditions we derive for (75) under its set reading:

$$
\begin{aligned}
& \llbracket \text { John knows every phone\# } \rrbracket^{\mathrm{w}, \mathrm{g}}= \\
& \forall x_{e}(\llbracket \text { phone\# }) \rrbracket^{\mathrm{w}, \mathrm{g}}(x) \rightarrow \forall w^{\prime} \in \operatorname{Dox}_{j}(w) \\
& \left.\quad\left(\llbracket \text { max phone\# } x_{1} \rrbracket^{\mathrm{w}^{\prime}, \mathrm{g}[1 / \mathrm{x}]}\right)=\left(\llbracket \text { max phone\# } x_{1} \rrbracket^{\mathrm{w}, \mathrm{g}[1 / \mathrm{x}]}\right)\right)
\end{aligned}
$$

In case John knows, for every existing phone number $x$, that $x$ is a phone number, (85) is true just as (78c) is. However, if John does not have the right knowledge about phone numbers, the sentence is correctly predicted to be false. This is because the descriptive trace to the left side of the equation in (85) is no longer undefined. Instead, it picks out the null individual for every possible phone number $x$ that is not a phone number in John's belief worlds. It follows, then, that the equation to the right of the arrow is false under at least some assignments. Given that the antecedent of the conditional is true under at least some assignments, the whole conditional is false. Hence, the formula in (85) correctly captures the fact that the sentence is false in this scenario.

To conclude: The copy theory of movement and Fox's trace conversion mechanism provided us with a way of accounting for set readings within the ICapproach. When we looked closely, however, the solution worked only for part of the data (just the true cases). The analysis wrongly predicted false sentences to lack a truth value (due to presupposition failure). In this section, I showed one way to solve this problem, by introducing a different definite operator during trace conversion. With the introduction of the maximality operator in (81), we derive the correct truth conditions for set readings. ${ }^{20}$

\footnotetext{
${ }^{19}$ Note that if both copy traces denoted the empty individual *, then the equation IImax Pred $x_{i} \rrbracket^{w, g}=\llbracket\left[\max\right.$ Pred $x_{i} \rrbracket \rrbracket^{w^{\prime}, g}$ would be true. Such cases never arise with factive predicates like know, but they are possible with nonfactive predicates (cf. Sect. 7.2).

20 The difficulty discussed in this section potentially generalizes to any use of Fox's copy traces, as long as intensional operators are involved. However, treatment of the general problem of the interaction of copy traces with intensional operators is beyond the scope of the present paper. I will leave a complete resolution of this issue for the future.
} 
5.5 A unified account of quantified and indefinite CQs

Quantified CQs with other types of 1-place predicate NPs can be accounted for in the same fashion. For instance, a sentence like (50), repeated below in (86a), will be analyzed as shown in (86c).

(86) a. Bob knows every member of the Italian soccer team.

b. Set reading: For every member of the Italian soccer team $x$, Bob knows that $x$ is a member of the Italian soccer team.

c. [every $\left(\mathrm{IT}_{\mathrm{socc}}-\right.$ member$\left.)\right] \lambda x_{1}$. Bob knows $\mathrm{CQ-se}$ [max $\mathrm{IT}_{\text {socc }}$-member $\left.x_{1}\right]$

The denotation of the descriptive trace can combine with know $w_{\mathrm{CQ}-\mathrm{se}}$ by IFA. Following an analogous computation to the one provided for the set reading of John knows every phone number, we arrive at a formula equivalent to (87).

$$
\begin{aligned}
& \llbracket \text { Bob knows every IT } T_{\text {socc }}-\text { member } \rrbracket^{\mathrm{w}, \mathrm{g}}= \\
& \forall x_{e}\left(x \text { is an } \mathrm { IT } _ { \text { socc } } - \text { member at } w \rightarrow \forall w ^ { \prime } \in \operatorname { D o x } _ { \mathrm { b } } ( w ) \left[x \text { is an } \mathrm{IT}_{\text {socc } \left.\left.- \text { member at } w^{\prime}\right]\right)}\right.\right.
\end{aligned}
$$

According to (87), (86a) is true in a world $w$ iff for every $x$ who is actually a member of the Italian soccer team at $w$, Bob believes that $x$ is a member of the Italian soccer team. These are the intuitive truth conditions of the sentence under its set reading.

Now that we have provided an analysis of set readings with quantified CQs, we could treat the indefinite examples in the same way. Thus, indefinite CQs, just like other quantified phrases, will have to undergo QR. When the NP-CQ is a 1-place predicate, as in (88a) below (repeated from (56b)), the copy trace at the bottom of the chain denotes an entity of type $e((88 \mathrm{c}))$, which can combine with $k n o w_{\mathrm{CQ}-\mathrm{se}}$ by IFA. $\lambda$-binding of the variable inside the descriptive trace creates a 1-place predicate that combines with the denotation of the indefinite CQ by FA, yielding the truth conditions in (89) below.

(88) a. Ram knows a shortcut to UMass.

b. [a UM-shortcut] Ram knows se [a UM-shortcut]

c. [a UM-shortcut] $\lambda \mathrm{y}_{\mathrm{e}}$ Ram knows $_{\mathrm{se}}\left[\max\right.$ UM-shortcut $\left.\mathrm{y}_{\mathrm{e}}\right]$

(89) $\llbracket$ Ram knows a shortcut to UMass $\rrbracket^{\mathrm{w}, \mathrm{g}}=$

$=\exists x_{e}[x$ is a UM-shortcut in $w \&$ $\forall w^{\prime} \in \operatorname{Dox}_{r}(w)\left(\llbracket \max U M\right.$-shortcut $x_{1} \rrbracket^{\mathrm{w}^{\prime}, \mathrm{g}[1 / \mathrm{x}]}=$ $\llbracket$ max $U M$-shortcut $\left.\left.x_{1} \rrbracket^{\mathrm{w}, \mathrm{g}[1 / \mathrm{x}]}\right)\right]$

$=\exists x_{e}\left[x\right.$ is a UM-shortcut in $w \& \forall w^{\prime} \in \operatorname{Dox}_{r}(w)\left(x\right.$ is a UM-shortcut in $\left.\left.w^{\prime}\right)\right]$

According to the formula above, (88a) is true in $w$ iff there is an actual shortcut to UMass in $w$ of which Ram believes that it is a shortcut to UMass. These truth 
conditions correctly describe the CQ-reading of (88a). Thus, it seems that our amended IC-approach can take care of the indefinite cases as well. ${ }^{21}$

\section{Pair-list readings revisited}

\subsection{Pair-list readings under the amended IC-approach}

Although we don't need to amend the IC-approach to account for pair-list readings, we could minimally modify the analysis given in Sect. 3 to make it consistent with our new view of traces. We will continue assuming that pair-list readings involve quantification over meaningfully sorted ICs. This is again achieved by applying Nathan's IC-shifter to 2-place NP-CQs (hence the correlation between pair-list readings and relational nouns). However, in the new version of the IC-approach, the trace left by movement of the quantified phrase is trace-converted into a copy containing a bound variable of type $<\mathrm{s}$,e $>$. The procedure is shown in (90)-(91) below.

(90) a. Mary knows every capital.

(pair-list reading)

b. [every IC(capital)] Mary knows ${ }_{\mathrm{CQ} \text {-se }}$ [every IC(capital)]

c. [every IC(capital)] $\lambda f_{\text {se. }}$ Mary knows CQ-se $_{\text {inax }}$ IC(capital) $\left.f_{\text {se }}\right]$

(91) Trace conversion (with variables of type $<\mathrm{s}, \mathrm{e}>$ )

a. Variable insertion: (Det) Pred $\rightarrow$ (Det) $\lambda g_{<\mathrm{s}, \mathrm{e}>}\left[\mathrm{IC}(\right.$ capital $\left.)(g) \& g=f_{1}\right]$

b. Determiner replacement: (Det) Pred $\rightarrow \max \left(\lambda g_{<\mathrm{s}, \mathrm{e}>}[\mathrm{IC}(\right.$ capital $)(g) \&$ $\left.\left.g=f_{1}\right]\right)$

In this case, the result of applying $\max$ to the extension of an IC-predicate returns (when the set is not empty) an individual concept, which can combine with know $_{\mathrm{CQ}-\mathrm{se}}$ by FA.

\footnotetext{
${ }^{21}$ Could the assumption that indefinite CQs must QR turn out to be problematic? Rajesh Bhatt (p.c.) suggests that sentences in which the CQ contains a negative polarity item (NPI) under the scope of a negative verb might turn out to be problematic. Consider (i) below.
}

(i) John is unaware of any mistakes in his proof.

If the indefinite NPI in (i) was a CQ, according to our account it should undergo QR. In this way, the $e$ typed descriptive trace left by movement could combine with the CQ-embedding predicate being unaware of (which presumably requires an IC-denoting internal argument) by IFA. Now, if the NPI underwent $\mathrm{QR}$, it would be outside the scope of its licensor (the negative verb being unaware of), whereas if it didn't move, it could not serve as the argument of the verb; hence the paradox. However, despite the existence elsewhere of clear CQ-readings with a predicate like being unaware of (see the examples in (ii) below), (i) above may in fact not have a real CQ-reading which we could paraphrase as 'John is unaware of what the mistakes in his proof are' or 'There are mistakes in John's proof but he is not aware of what they are'. The judgments I collected leave unclear whether (i) has such a CQ-reading, or whether the sentence simply means that John is not aware of mistakes in his proof (which may or may not exist).

(ii) a. Many people are unaware of the calorie content of alcohol. (BBC News, April 17, 2009)

b. Many consumers are unaware of the price they pay for milk, and their busy lifestyles preclude them from shopping around for the best milk prices. (found by Google at www.consumersunion.org/other/sacrptwc299.htm) 
(92) Mary knows every capital

(pair-list reading)

a.

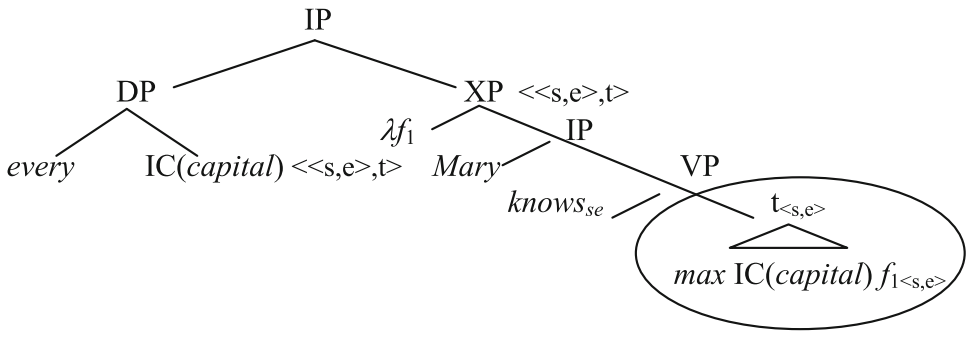

b. For any constituent $\alpha$ and variable assignment $g, \llbracket \lambda_{\mathrm{i}, \mathrm{T}} \alpha \rrbracket^{\mathrm{w}, \mathrm{g}}=$ $\lambda x_{\mathrm{T}} \cdot \llbracket \alpha \rrbracket^{\mathrm{w}, \mathrm{g}[\mathrm{i} / \mathrm{x}]}$

c. $\llbracket$ Mary knows every capital $\rrbracket^{\mathrm{w}, \mathrm{g}}=$ $\forall f_{<s, e>}\left[\exists x_{\mathrm{e}} \forall w^{*}\left[f\left(w^{*}\right)\right.\right.$ is the capital of $x$ at $\left.w^{*}\right] \rightarrow$ $\forall w^{\prime} \in \operatorname{Dox}_{m}(w)\left[\llbracket \max I C\left(\right.\right.$ capital) $f_{l} \rrbracket^{\mathrm{w}, \mathrm{g}[1 / \mathrm{f}]}\left(w^{\prime}\right)=$ $\llbracket \max I C\left(\right.$ capital) $\left.\left.f_{1} \rrbracket^{\mathrm{w}, \mathrm{g}[1 / \mathrm{f}]}(w)\right]\right]$

In this case, the content of the descriptive traces is semantically redundant-because the property denoted by IC(capital) is not world-dependent and is already guaranteed by the restriction of the quantifier. Thus, the formula above reduces to the simpler formula in (43b), repeated below.

$$
\begin{aligned}
& \llbracket \text { Mary knows every capital } \rrbracket^{\mathrm{w}, \mathrm{g}}= \\
& \forall f_{<s, e>}\left(\left(\exists x_{\mathrm{e}} \forall w^{*}\left[f\left(w^{*}\right) \text { is capital-of } x \text { at } w^{*}\right]\right) \rightarrow\right. \\
& \left.\forall w^{\prime} \in \operatorname{Dox}_{m}(w)\left[f\left(\mathrm{w}^{\prime}\right)=f(\mathrm{w})\right]\right)
\end{aligned}
$$

\subsection{A problem: pair-list readings with nonfunctional nouns}

In this section, I point out a problem for the IC-approach concerning pair-list readings with nouns that are relational but not functional. In the original version of the IC-approach, as well as in the revised version, pair-list readings are analyzed as involving quantification over meaningfully sorted ICs. Quantification over ICs (as opposed to individuals) is implemented, under both versions of the IC-approach, by applying Nathan's IC-shifter to the denotation of a 2-place predicate. 2-place predicates could be functional (denoting a function from individuals to individuals) or simply relational (denoting a relation between individuals). So far, we have ignored this distinction and worked primarily with functional nouns such as price, or capital. However, a closer look at pair-list readings with nouns that are relational but not functional will reveal that Nathan's IC-shifter is only suitable for creating IC-predicates from functional nouns. I propose that pair-list readings with nonfunctional relational head nouns should be accounted for by quantifying over pairs of individuals rather than individual concepts. 


\subsubsection{Failure of the IC-shifter}

We have focused so far on nouns like capital, price, etc., which are not just relational but also functional. However, pair-list readings are also possible with relational nouns that are not functional, as shown by (94).

(94) Julia knows every phone number.

Nowadays, people may have multiple phone numbers, corresponding to their landline, cell-phone, office, etc. Thus, a noun like phone number is relational, but not necessarily functional. In fact, while (95a) is a perfectly natural sentence, (95b) is not.

(95) a. The secretary knows every phone number of Dr. Smith.

b. \#The cashier knows every price of milk.

Notice that Nathan's IC-shifter is defined to apply to relational nouns in general, whether functional or not. Thus, an application of Nathan's IC-shifter to phone number would create the IC-predicate in (96).

$$
\llbracket \mathrm{IC}(\text { phone\# }) \rrbracket^{\mathrm{w}, \mathrm{g}}=\lambda f_{<\mathrm{s}, \mathrm{e}}>\exists x_{\mathrm{e}} \forall w^{\prime} \llbracket \text { phone\# } \rrbracket^{\mathrm{w}^{\prime}, \mathrm{g}}(x)\left(f\left(w^{\prime}\right)\right)
$$

However, there is a problem. If a given person has more than just one phone number, Nathan's IC-shifter no longer individuates ICs in the right way. To see why, consider a very simple model with only two possible worlds, $\mathrm{w}_{0}$ and $\mathrm{w}^{\prime}$. Suppose further that there exist only two individuals, Mary and Sue, and that at both worlds Mary has two phone numbers, 413-000 and 414-000, whereas Sue has only one phone number, 415-000 (below, I simplify the phone numbers by omitting the last 3 digits).

(97) Toy model: $\mathrm{w}_{0}$ : Mary has phone numbers 413 and 414,

Sue has phone number 415

$\mathrm{w}^{\prime}$ : Mary has phone numbers 413 and 414 ,

Sue has phone number 415 ;

other irrelevant differences from $\mathrm{w}_{0}$

Now suppose that $\mathrm{w}_{0}$ is the actual world, whereas $\mathrm{w}^{\prime}$ is the world according to Julia's beliefs; thus Julia has the right knowledge of phone numbers. Intuitively, in these circumstances, the pair-list reading of (94) should come out true. However, an application of Nathan's type-shifter would cause the sentence to come out as false. Indeed, by applying the IC-shifter to telephone number as defined in our toy model, we would create the set of ICs in (98).

(98) $\llbracket \mathrm{IC}($ phone\#) $) \rrbracket^{\mathrm{w}}=\lambda f_{<\mathrm{s}, \mathrm{e}>} \exists x_{\mathrm{e}} \forall w^{*}\left[f\left(w^{*}\right)\right.$ is a phone number of $x$ at $\left.w^{*}\right]$

$$
\left\{\left(\begin{array}{l}
w_{0} \rightarrow 413 \\
w^{\prime} \rightarrow 413 \\
c_{1}
\end{array}\right),\left(\begin{array}{l}
w_{0} \rightarrow 414 \\
w^{\prime} \rightarrow 414 \\
c_{2}
\end{array}\right),\left(\begin{array}{l}
w_{0} \rightarrow 415 \\
w^{\prime} \rightarrow 415 \\
c_{3}
\end{array}\right),\left(\begin{array}{l}
w_{0} \rightarrow 413 \\
w^{\prime} \rightarrow 414 \\
c_{4}
\end{array}\right),\left(\begin{array}{l}
w_{0} \rightarrow 414 \\
w^{\prime} \rightarrow 413 \\
c_{5}
\end{array}\right)\right\}
$$


Each IC in this set is a properly individuated concept, according to Nathan's IC-shifter. Nevertheless, if this turns out to be our domain of quantification, we would wrongly predict the sentence to be false in the described scenario because IC(phone\#) contains functions such as $\mathrm{c} 4$ and $\mathrm{c} 5$, whose values are different at $\mathrm{w}_{0}$ and $\mathrm{w}^{\prime}$.

One may try to fix this problem by having each individual concept in IC(phone\#) map every world $w$ into the sum of $x$ 's phone numbers at $w$. If we allow this option, the denotation of IC(phone\#) in our toy model would be the set of ICs in (99).

$$
\left\{\left(\begin{array}{l}
w_{0} \rightarrow 413+414 \\
w^{\prime} \rightarrow 413+414 \\
c_{1}
\end{array}\right), \quad\left(\begin{array}{l}
w_{0} \rightarrow 415 \\
w^{\prime} \rightarrow 415 \\
c_{2}
\end{array}\right)\right\}
$$

Given (99), we would now correctly predict the sentence Julia knows every phone number to be true in our toy model, because it is true that each individual concept denoted by IC(phone\#) yields the same value at $\mathrm{w}_{0}$ and at Julia's belief worlds $\mathrm{w}^{\prime}$.

However, although this adjustment would solve the problem for quantified CQs headed by every, it would not work with CQs headed by other quantifiers, such as numerals, no, or most, as in (100) below.

(100) a. Julia knows three phone numbers.

b. Julia knows no phone numbers.

c. Julia knows most phone numbers.

In all of these examples, we seem to be counting pairs consisting of a person and one of his/her phone numbers, not just holders of phone numbers. Take (100a), for example. Given the circumstances described in our toy model, (100a) is intuitively true since Julia knows a total of three telephone number/individual pairs: two telephone numbers of Mary and one telephone number of Sue. However, if (99) is the denotation of IC(phone\#) in our toy model, there will be only two ICs in our domain of quantification instead of three. Therefore, the sentence would come out false, contrary to our intuitions.

Similarly, consider (100b) in a slightly modified scenario, like the one summarized in (101) below. Assume again that $w_{0}$ is the actual world and $\mathrm{w}^{\prime}$ is the world according to Julia's beliefs. This time, though, Julia is wrong about all phone numbers except one-namely, one of Mary's phone numbers.

(101) Toy model: $\mathrm{w}_{0}$ : Mary has phone\#s 413 and 414,

Sue has phone\# 415

$\mathrm{w}^{\prime}$ : Mary has phone\#s $\mathbf{4 1 3}$ and 417,

Sue has phone\# 416;

other irrelevant differences from $\mathrm{w}_{0}$

Intuitively, under the circumstances described in the toy model above, (100b) should be false, given that Julia is right about one telephone number. However, if the set of ICs denoted by IC(phone\#) is the set in (102), we would wrongly predict 
the sentence to be true in the given scenario, since it is true that all the ICs in this set yield different values at $w_{0}$ and $w^{\prime}$.

$$
\left\{\left(\begin{array}{c}
w_{0} \rightarrow 413+414 \\
w^{\prime} \rightarrow 413+417 \\
c_{1}
\end{array}\right),\left(\begin{array}{c}
w_{0} \rightarrow 415 \\
w^{\prime} \rightarrow 416 \\
c_{2}
\end{array}\right)\right\}
$$

Because of the facts just discussed it seems reasonable to conclude that the ICshifter is not the right tool to capture pair-list readings for CQs headed by nonfunctional relational nouns.

\subsubsection{The PAIR-shifter}

Correct results obtain if instead of Nathan's IC-shifter, we employ a new typeshifter, defined in (103) below.

$$
\llbracket \operatorname{PA} \operatorname{IR}(\alpha) \rrbracket^{\mathrm{w}, \mathrm{g}}=\lambda r_{e} \cdot \exists x_{\mathrm{e}} \cdot \exists y_{\mathrm{e}} \cdot \mathrm{r}=<x, y>\& \llbracket \alpha \rrbracket^{\mathrm{w}}(x)(y)
$$

(treating ordered pairs as included in $\mathrm{D}_{\mathrm{e}}$ )

Applying the PAIR-shifter to the denotation of a relational noun like phone number returns a predicate of pairs (104).

\section{$\llbracket \operatorname{PAIR}(\text { phone\#) }]^{\mathrm{w}, \mathrm{g}}=\lambda r_{e} . \exists x_{\mathrm{e}}\left[\exists y_{\mathrm{e}}[r=<x, y>\&\right.$}

$y$ is a phone number of $x$ at $w]]$

When the PAIR-shifter is used, the object of know $w_{\mathrm{CQ}-\mathrm{se}}$ is a function from possible worlds into pairs of individuals (e.g., a person and one of her/his phone numbers). The pair-list reading of (94) has the LF in (105c) below.

(105) a. Julia knows every telephone number.

b. Pair-list reading: For every pair $\langle\mathrm{x}, \mathrm{y}\rangle$ such that $\mathrm{y}$ is a telephone number of $\mathrm{x}$, Julia knows that $\mathrm{y}$ is a telephone number of $\mathrm{x}$.

c. every PAIR(phone number) $\lambda r_{\mathrm{e}} \mathrm{J}_{\text {. knows }}$ (Q-se $_{\text {(max }}$ PAIR(phone\#) $\left.\mathrm{r}\right]$

Since the denotation of the descriptive trace is by assumption a definite of semantic type e, it must combine with know $_{\mathrm{CQ} \text {-se }}$ by IFA. $\lambda$-binding of the variable inside the descriptive trace creates a predicate of pairs which combines with the denotation of every phone number by FA, yielding the truth conditions in (106).

(106) 【Julia knows ${ }_{C Q-s e}$ every phone $\# \rrbracket^{\mathrm{w}, \mathrm{g}}$

$$
\begin{aligned}
= & \forall r_{e}\left[\llbracket \operatorname { P A I R } \left(\text { phone\#) } \rrbracket^{\mathrm{w}, \mathrm{g}}(r) \rightarrow \forall w^{\prime} \in \operatorname{Dox}_{J}(w)\right.\right. \\
& \left(\llbracket \text { max } \operatorname{PAIR}\left(\text { phone\#) } r_{1} \rrbracket^{\mathrm{w}^{\prime}, \mathrm{g}[1 / \mathrm{r}]}=\llbracket \text { max } \operatorname{PAIR}\left(\text { phone\#) } r_{1} \rrbracket^{\mathrm{w}, \mathrm{g}[1 / \mathrm{r}]}\right)\right]\right. \\
= & \forall r_{e}\left[\exists x _ { \mathrm { e } } \left[\exists y_{\mathrm{e}}[\mathrm{r}=<\mathrm{x}, \mathrm{y}>\& y \text { is a phone number of } x \text { at } w] \rightarrow\right.\right. \\
& \left.\left.\forall w^{\prime} \in \operatorname{Dox}_{J}(w)\left(\llbracket \operatorname{PAIR}(\text { phone\# }) \rrbracket^{\mathrm{w}^{\prime}}(r)\right)\right]\right]
\end{aligned}
$$


According to the formula above, (105a) is true in the actual world $w$ iff for every pair $r$ consisting of an individual and one of his/her phone numbers, Julia believes that the two individuals forming the pair $r$ are in the 'phone-number-of' relation. These are the intuitive truth conditions of the sentence under its pair-list reading.

\subsubsection{Why the IC-shifter cannot be eliminated}

At this point one may wonder whether we should eliminate the IC-shifter altogether, and replace it with the PAIR-shifter whenever we need to derive pair-list readings. Although this move may seem attractive, as it would simplify the analysis quite a bit, the IC-shifter does not always reduce to the PAIR-shifter. In fact, the IC-shifter seems necessary to account for the meaning of (107) below (from M. Kaufmann, p.c.).

(107) John knows the price that hasn't yet been determined.

Assume that the price that hasn't yet been determined is the price of milk. In this case, (107) is interpreted as meaning: 'John knows that the price of milk is the price that hasn't yet been determined'. It is obvious that for (107) to be true, John does not have to believe that milk costs what it costs (given that its price hasn't been fixed yet), nor that the pair consisting of milk and its price in dollars stand in the 'price-of' relation. Instead, what has to have the same value in John's belief worlds and in the actual world is the complex concept picked out by the price that hasn't yet been determined. What (107) says is that this concept (of semantic type $<\mathrm{s},<\mathrm{s}$,e $>>$ ) must have the same extension in the actual world and in John's belief worlds; i.e. the extension of this function in John's belief worlds must be the individual concept the price of milk. The meaning of (107) can be rendered along the lines of (108) below: ${ }^{22}$

(108) J.knows ${ }_{\mathrm{CQ}<\mathrm{s},<\mathrm{s}, \mathrm{e}>>}\left[\right.$ the IC(price) $\lambda \mathrm{f}_{\mathrm{se}}$. the $\mathrm{t}_{\mathrm{f}}$ IC(price) not-determined $\left.{ }_{<\mathrm{s}, \mathrm{e}>}\right]$

Here is another example, which one could address in the same way. The example is due to Philip Bricker (p.c.) and it goes like this: suppose the country of Fredonia is a kingdom where it is established that the next ruler of the country is always going to be the first legitimate heir of the current reigning couple. Suppose John, a citizen of Fredonia, knows this fact: would we assent to the truth of (109) even if the next ruler of Fredonia has not been born yet? The answer seems to be yes.

(109) John knows the next ruler of Fredonia.

Setting aside an implausible acquaintance reading, (109) in this scenario does not express a belief towards a particular individual who happens to be the next ruler of Fredonia, given that such individual does not exist (yet), nor towards a pair consisting of a country and his ruler. Instead, it expresses a belief towards a

\footnotetext{
22 Here, I am following Romero (2005) in assuming a flexible denotation for $k n o w_{\mathrm{CQ}}$ that can derive readings with arbitrary high meta-knowledge (by FA or IFA).
}

(i) $\llbracket \mathrm{know}_{\mathrm{CQ}} \rrbracket^{\mathrm{w}}=\lambda \underline{y}_{\tau} \lambda \mathrm{x}_{\mathrm{e}} \forall \mathrm{w}^{\prime} \in \operatorname{Dox}_{\mathrm{x}}(\mathrm{w})\left[\underline{y}\left(\mathrm{w}^{\prime}\right)=\underline{y}(\mathrm{w})\right]$ where $\tau=<\mathrm{s}, \mathrm{e}>$ or $<\mathrm{s},<\mathrm{s}, \mathrm{e}>>$ or $\ldots$ 
particular individual concept-in this case, the IC the first heir of the current reigning couple of Fredonia. Like before, the DP-CQ 'the next ruler of Fredonia' will denote a more complex concept of type $\langle\mathrm{s},\langle\mathrm{s}$,e $\rangle>$, and it is the extension of such a function that has to be the same at the actual world and at John's belief worlds (i.e., John believes that the next ruler of Fredonia is the first heir of the current reigning couple of Fredonia, whoever that individual may be).

More complex examples that also seem to point to the conclusion that the IC-shifter cannot be replaced by the PAIR-shifter involve nested CQs. Heim (1979) discovered that sentences with nested CQs, such as (110), have two possible readings: assuming that the only capital that Fred knows is the capital of Italy, (110) is ambiguous between a 'question' $(\mathrm{Q})$ reading and a 'meta-question' (MQ) reading. ${ }^{23}$

(110) John knows the capital that Fred knows.

(Heim 1979)

Q-reading (A): Fred knows the capital of, say, Italy, and John knows it too. (I.e., John, like Fred, knows the answer to the question 'What is the capital of Italy?')

MQ-reading (B): John knows which capital Fred knows. (I.e., John knows the answer to the meta-question 'Which capital-question does Fred know the answer to?')

Without getting into the details of how one may account for such ambiguity (see Heim 1979; Romero 2005; Roelofsen and Aloni 2008; Schwager 2008; Percus 2009; Frana 2010, a.o.), I simply want to point out that MQ-readings cannot be derived with the PAIR-shifter. In intuitive terms, this is due to the fact that-under this reading-the sentence is true as long as John is able to tell which capitalquestion Fred knows the answer to, without knowing the answer to this question himself. Thus, John does not have to have a belief towards a particular pair consisting of a country and its capital. Rather, what we are checking is the value of a higher concept of semantic type $<\mathrm{s},<\mathrm{s}, \mathrm{e}>>$ across different worlds. ${ }^{24}$

\footnotetext{
${ }^{23}$ Roelofsen and Aloni (2008) observe that sentences with nested quantified CQs like 'John knows every capital that Fred knows' are actually 4-way ambiguous, as a result of the interaction between set/pair-list readings and Heim's Q/MQ ambiguity. In Frana (2010) I propose an account of this ambiguity within the general approach given in this paper. For alternative accounts see Roelofsen and Aloni (2008), Aloni and Roelofsen (2011), Percus (2009, 2010), and Romero (2010).

24 Although it is beyond the scope of this paper to discuss higher-typed readings, it should be pointed out that when applied to sentences with CQs denoting individual concepts (Q-readings) or intensions of individual concepts (MQ-readings), the IC-approach can derive their truth conditions with the tools at hand, i.e. the IC-shifter, Romero's flexible denotation for know, (c.f. footnote 22) and (intensionalized) FA. However, for higher-typed CQs (where the intension of the CQ is of type $\langle\mathrm{s},\langle\mathrm{s},\langle\mathrm{s}, \mathrm{e}\rangle\rangle\rangle$ ) -as in example (i) below from Romero-we would also need an entry for the NP-CQ predicate that characterizes a set of $\langle\mathrm{s},\langle\mathrm{s}, \mathrm{e}\rangle\rangle$ concepts. This would require the introduction of a different IC-shifter (or a family of IC-shifters) from the one used in this paper. Reflections on this point are left to further research. Thanks to an anonymous NALS reviewer for bringing this issue to my attention.
}

(i) John knows the price Fred knows: the price announced yesterday morning. (Romero 2005, p. 695) (Fred knows the answer to the MQ 'What price was announced yesterday morning?', while John knows the answer to the MMQ 'What price does Fred know?'.) 
To conclude: We saw that in the case of pair-list readings with relational nouns that are not functional, Nathan's IC-shifter no longer generates a suitable domain of quantification. Correct results obtain if instead of Nathan's IC-shifter, one employs the PAIR-shifter defined in (103), which shifts the denotation of a 2-place predicate into a predicate of pairs. In this way, pair-list readings with nonfunctional relational nouns are rendered by quantifying over pairs of individuals, instead of properly individuated ICs. However, the PAIR-shifter cannot substitute for Nathan's ICshifter in all cases, and quantification or abstraction over variables of type $<$ s,e $>$ cannot be completely eliminated from the grammar.

\section{Further issues}

\subsection{Set readings with temporally intensional verbs}

An individual-concept-based analysis of pair-list and set readings, like the one given in this paper, leads us to expect that these readings should appear not only with CQsentences but, more generally, with sentences whose main verb selects for individual concepts. In fact, this seems to be the case. Consider the following example from Nathan (2006).

(111) After the elections, every governor changed.

The example above has a quantified NP subject (whose head noun is relational) and the verb change, which-under its intensional interpretation-selects for individual concepts. As Nathan points out, (111) has two possible interpretations. ${ }^{25}$ Under one of these interpretations, the sentence is true if and only if the whole set of governors before the elections is replaced by an entirely new set of governors after the elections. Under the other interpretation, the sentence can be true if the overall set of governors stays the same from one time to another, but the individual governors swap their jobs (i.e., the governor of Maine at index i becomes the governor of Massachusetts at index $i^{\prime}$, and so on). Schwager (2007) calls the type of change involved in the first reading set change and that involved in the second type of reading pointwise change. Furthermore, Nathan notes that pointwise change readings are not always available. Compare the example above with (112), where the head noun of the NP subject (song) is not relational. Intuitively, while (111) can be true in a situation in which the overall set of governors stays the same across time but the individual governors swap their jobs, a sentence like (112) can only mean that every song in Jan's iTunes library has been replaced with a new one and that the resulting set of songs is different from one time to the other (set change).

(112) (After Meredith made fun of his musical taste, ) every song in Jan's iTunes library changed.

\footnotetext{
25 There is also a third, 'extensional' reading (according to which each governor changed some of his/her personal features), which does not concern us here.
} 
Set change and pointwise change readings bear a striking resemblance to set and pair-list readings of quantified CQs. In fact, I argue that they are exactly the same phenomenon: set change readings are just like set readings in that they appear with 1-place predicate NPs and involve quantification over individuals, whereas pointwise change readings are just like pair-list readings in that they appear with 2-place predicate NPs and involve quantification over individual concepts, or pairs.

Consider another example of a set change reading:

(113) Every bodyguard of Arnold changed.

(Schwager 2007)

The sentence in (113) has two readings, an extensional and an intensional one. Assume that Arnold has two bodyguards, Bruce and Duke. Under the first (extensional) reading of (113), the sentence says something about Bruce and Duke in their role as bodyguards, i.e. that they changed some of their personal qualities. Under the second (intensional) reading, (113) says that Arnold's bodyguards are no longer the same, i.e. Bruce and Duke have been replaced. According to Schwager, in the first case, change acts as a predicate of individuals, while in the second reading, it acts as a predicate of individual concepts. If we accept this reasoning, then we have to face the following question: what are the individual concepts that we are quantifying over in (113)? Given that we are talking about the bodyguards of Arnold, we obviously cannot individuate these functions via the internal argument of the relational noun. Moreover, if the internal argument of the relational noun has been saturated (by the individual denoted by Arnold), an application of the IC-shifter is not even possible, since this type-shifter can only apply to relational nouns. Clearly, this is the same problem raised by quantified CQs with 1-place predicate NPs (set readings). Without drawing comparisons with existing accounts of these data (see Nathan 2006 and Schwager 2007), the point I want to make here is simply that the analysis of set readings given in this paper extends to the apparently problematic set change readings as well. Thus, (113) can be analyzed as shown in (114). Since the trace in base position is a copy with descriptive content, the verb can operate on the intension of the copy trace by Intensional Functional Application. ${ }^{26}$

(114) [every bodyguard of Arnold] $\lambda x_{i}\left[\right.$ max bodyguard of $\left.A . x_{i}\right]$ has changed $<s, e>$

To conclude: the fact that pair-list and set readings are found with quantified NPs in temporally intensional contexts (i.e., with verbs like change that also select for individual concepts) further supports an individual-concept-based analysis of quantified CQs.

\subsection{Set readings with nonfactive verbs}

The way the present account derives set readings crucially relies on two mechanisms: $\mathrm{QR}$ and descriptive traces. Thus, the set reading of a quantified CQ-sentence is derived as shown below.

\footnotetext{
${ }^{26}$ In order to derive the truth conditions of (114), we need to think about the lexical semantics of temporally intensional verbs, like change, and about the way the temporal dependency introduced by the verb interacts with tense and aspect. I will leave this point open for future research.
} 
(115) a. John knows every phone number (in this office).

b. [every $\operatorname{IOD}\left(\right.$ phone\#)] $\lambda \mathrm{x}_{1}$ John knows ${ }_{\mathrm{CQ} \text {-se }}\left[\max \operatorname{IOD}\left(\right.\right.$ phone\#) $\left.\mathrm{x}_{1}\right]$

Note that this way of deriving set readings always amounts to quantifying over actual instantiations of the predicate NP-in the case at hand, over actual phone numbers (because of QR, the quantified DP is interpreted outside the scope of the intensional verb). With factive verbs like know, this is not an issue. However, as an anonymous reviewer points out, set readings are also possible with nonfactive verbs like agree on. Consider the following scenario:

Reviewer's scenario: John and Mary are the two secretaries in an office. Although they are both quite chaotic, they are usually reliable when they agree on some piece of information. The office manager, Smith, needs to assign a phone extension that is not yet taken by anybody in the office to a new employee. He asks John and Mary what the (already assigned) extensions are. John tells him 212, 213, and 214. Mary tells him the same. But in fact John's and Mary's shared belief is completely wrong this time: the phone numbers already assigned are 215, 216, and 217.

(116) Smith: John and Mary disagree on many things, but they agree on every phone number. So I will trust them on this and choose a number different from the ones they gave me.

As the reviewer points out, the underlined statement in (116) is true in the above scenario. However, when interpreting (116), we seem to confine our attention to those numbers that are phone numbers according to John and Mary, not to actual phone numbers. Suppose that agree on has a lexical entry that selects for individual concepts, just like know $_{\mathrm{CQ} \text {-se }}$, except that in this case, we are comparing the value of a concept across (at least) two sets of doxastic alternatives. The entry in (117) below, which adopts Lahiri's (2002) idea that the lexical semantics of agree on is inherently reciprocal (and thus based on agree with), would serve our purposes.

(117) Semantics for agree on $<\mathrm{s,e}>$ :

Agree (w) (X) (f) iff for all $\mathrm{x}, \mathrm{y}$ in $\mathrm{X}$ :

$\forall \mathrm{w}^{\prime} \operatorname{Dox}_{\mathrm{x}}(w) \forall \mathrm{w}^{\prime \prime} \operatorname{Dox}_{\mathrm{y}}(w): \mathrm{f}\left(w^{\prime}\right)=\mathrm{f}\left(w^{\prime \prime}\right)$

(118) a. John and Mary agree on Sue's phone number.

b. $\forall \mathrm{w}^{\prime} \operatorname{Dox}_{\mathbf{j}}(w) \forall \mathrm{w}^{\prime \prime} \operatorname{Dox}_{\mathrm{m}}(w)$ :

SUE'S PHONE NUMBER $\left(w^{\prime}\right)=\operatorname{SUE}$ 'S PHONE NUMBER $\left(w^{\prime \prime}\right)$

Let us return now to set readings. Our analysis would assign the following LF and truth conditions to a sentence like John and Mary agree on every phone number (under the set reading). In (119b) below, read phone\# as IOD(phone\#).

(119) a. [every (phone\#)] $\lambda \mathrm{x}_{1}$ J.\&M. agree ${ }_{\mathrm{CQ}-\mathrm{se}}\left[\max\right.$ (phone\#) $\mathrm{x}_{1}$ ]

b. $\forall x_{e}(\llbracket p h o n e \#) \rrbracket^{\mathrm{w} 0}(x) \rightarrow \forall w^{\prime} \in \operatorname{Dox}_{j}\left(w_{0}\right) \forall \mathrm{w}^{\prime \prime} \operatorname{Dox}_{\mathrm{m}}\left(w_{0}\right)$ : $\left(\llbracket \max\right.$ phone\# $x_{1} \rrbracket^{\mathrm{w}^{\prime}, \mathrm{g}[1 / \mathrm{x}]}=\llbracket \max$ phone\# $\left.\left.x_{1} \rrbracket^{\mathrm{w}^{\prime \prime}, \mathrm{g}[1 / \mathrm{x}]}\right)\right)$ 
Unfortunately, this formula overgeneralizes. In case John and Mary do agree on every phone number and their beliefs are correct, the formula correctly predicts the sentence to be true. In the reviewer scenario, where John and Mary agree on every phone number but their beliefs are incorrect, the formula is also true-given that both descriptive traces would return the null individual, resulting in the tautological (embedded) proposition ' $*=*$ '. However, the formula above predicts the sentence to be true as long as $x$ is a phone number in the actual world but not a phone number in John and Mary's belief worlds, even if John and Mary do not, in fact, agree on any phone number. It seems, then that the account of set readings given for factive predicates does not naturally extend to nonfactive predicates. It could be that the maximality operator needs further refinements, or that the lexical semantics for agree on differs in substantial ways from the simplified entry in (117). Investigating this issue, however, would require more time and space than available here.

\section{Conclusions}

In this paper I proposed an account of quantified CQs with different types of NPpredicates - an account which derives the truth conditions of pair-list and set readings. I argued that the availability of pair-list vs. set readings correlates with the type of NP-CQ involved (functional, relational, or nonrelational). Table 1 below provides sample sentences for each type of NP-CQ and shows how different CQreadings are derived within the proposed account.

As shown in Table 2 below, pair-list readings correlate with 2-place NP predicates and involve either quantification over meaningfully sorted concepts (functional nouns) or quantification over pairs of individuals (relational nouns). Set readings, on the other hand, correlate with 1-place NP predicates (these are

Table 1 The distribution of pair-list and set readings

\begin{tabular}{llll}
\hline Sample sentence & Type of noun/shifter & Pair-list reading & Set reading \\
\hline Sally knows every capital. & 2-Place: IC(capital) & $\sqrt{ }$ & $\sqrt{ }$ \\
& 1-Place: IOD(capital) & & \\
The secretary knows every phone number. & 2-Place: PAIR(phone\#) & $\sqrt{ }$ & $\sqrt{ }$ \\
Sally knows every book you like. & 1-Place: IOD(phone\#) & $\sqrt{ }$ \\
\hline
\end{tabular}

Table 2 Shifter/reading correlations

\begin{tabular}{llll}
\hline Type of NP-CQ & Shifter & Domain of quantification & Reading \\
\hline 2-Place (functional) & IC-shifter & Meaningfully sorted concepts & Pair-list \\
2-Place (not functional) & PAIR-shifter & Pairs of individuals & Pair-list \\
2-Place & IOD-shifter & Individuals & Set \\
1-Place & No shifter & Individuals & Set \\
\hline
\end{tabular}


predicates whose head noun is either lexically nonrelational or consists of a relational noun whose internal argument has been saturated overtly or covertly via IOD) and involve quantification over individuals.

Regardless of the type of noun involved, the account of quantified CQs given in this paper relies on the following two syntactic assumptions: (i) the quantified phrase is not interpreted in situ (i.e., it undergoes QR); and (ii) the trace left in base position is a copy with semantic content. The account itself is cast within the ICapproach (Heim 1979; Romero 2005), i.e. it postulates that a CQ-embedding predicate, like know, selects for individual concepts. ${ }^{27}$

Acknowledgments This article is based upon a part of my Ph.D. dissertation (Frana 2010), although the details of the analysis are not exactly the same. I would like to thank my committee members, Angelika Kratzer, Irene Heim, Rajesh Bhatt, and Philip Bricker, for their invaluable help. Thanks also to Magdalena Kaufmann, Paula Menéndez-Benito, Kyle Rawlins, and two anonymous NALS reviewers for their comments and suggestions, which improved the final version of the paper. A talk based on this material was presented at NELS 41. I am grateful to the participants of this event, especially to Maria Aloni and Maribel Romero. All mistakes are my own.

Open Access This article is distributed under the terms of the Creative Commons Attribution License which permits any use, distribution, and reproduction in any medium, provided the original author(s) and the source are credited.

\section{References}

Aloni, Maria. 2008. Concealed questions under cover. In Knowledge and questions (Grazer Philosophische Studien 77), ed. Franck Lihoreau, 191-216. Graz: University of Graz.

Aloni, Maria, and Floris Roelofsen. 2011. Resolving concealed questions. Linguistics and Philosophy 34: 443-478.

Barker, Chris. 1995. Possessive descriptions. Stanford: CSLI Publications.

Carlson, Gregory. 1977. Reference to kinds in English. PhD diss., University of Massachusetts, Amherst, MA: GLSA.

Chomsky, Noam. 1995. The minimalist program. Cambridge, MA: MIT Press.

Chung, Sandra, and William Ladusaw. 2004. Restriction and saturation (Linguistic Inquiry Monographs 42). Cambridge, MA: MIT Press.

Fox, Danny. 1999. Reconstruction, binding theory and the interpretation of chains. Linguistic Inquiry 30: 157-196.

Fox, Danny. 2002. Antecedent contained deletion and the copy theory of movement. Linguistic Inquiry 33: 63-96.

Frana, Ilaria. 2006. The de re analysis of concealed questions. A unified approach to definite and indefinite concealed questions. In Proceedings of SALT 16, ed. M. Gibson and J. Howell, 17-34. Ithaca, NY: CLC Publications.

Frana, Ilaria. 2010. Concealed questions. In search of answers. PhD diss., University of Massachusetts at Amherst.

Grimshaw, Jane. 1979. Complement selection and the lexicon. Linguistic Inquiry 10: 279-326.

Harris, Jesse. 2007. Revealing concealment: A (neuro-)logical investigation of concealed questions. Master of Logic thesis, Institute for Logic, Language, and Computation at the University of Amsterdam.

\footnotetext{
27 It is worth pointing out that the analysis of quantified CQs given in this paper is also compatible with a property-based analysis of CQs (c.f. Frana 2006; Schwager 2007). Under the assumption that an individual concept can always be shifted into the corresponding property via IDENTIFY (a variant of Partee's (1986) type-shifter IDENT), a property-based analysis is equivalent to an IC-based analysis.
}

(i) $\llbracket$ IDENTIFY $\rrbracket=\lambda f_{<\mathrm{s}, \mathrm{e}}>\lambda w \cdot \lambda x_{\mathrm{e}} x=f(w)$

(Frana 2006) 
Heim, Irene. 1979. Concealed questions. In Semantics from different points of view, ed. R. Bäuerle, U. Egli, and A. von Stechov, 51-60. Berlin: Springer.

Heim, Irene, and Angelika Kratzer. 1998. Semantics in generative grammar. Malden, MA: Blackwell.

Kratzer, Angelika. 1990. How specific is a fact? In Proceedings of the conference on theories of partial information. Austin: Center of Cognitive Science, University of Texas.

Kratzer, Angelika. 2002. Facts: Particulars or information units? Linguistics and Philosophy 25: 655-670.

Lahiri, Utpal. 2002. Questions and answers in embedded contexts. Oxford: Oxford University Press.

May, Robert. 1977. The grammar of quantification. PhD diss., MIT.

Montague, Richard. 1974. The proper treatment of quantification in ordinary English. In Formal philosophy: Selected papers by Richard Montague, ed. R.H. Thomason, 247-270. New Haven: Yale University Press. (Reprinted in Formal semantics: The essential readings, ed. P. Portner and B. Partee, 17-34, Blackwell, 2002).

Nathan, Lance. 2006. On the interpretation of concealed questions. PhD diss., MIT.

Partee, Barbara. 1983/1997. Uniformity vs. versatility: The genitive, a case study. Appendix to Theo Janssen, Compositionality. In The handbook of logic and language, ed. J. van Benthem and A. ter Meulen, 464-470. New York: Elsevier, 1997.

Partee, Barbara. 1986. Noun phrase interpretation and type-shifting principles. In Formal semantics, The essential readings, ed. P. Portner and B. Partee, 357-381. Malden: Blackwell.

Percus, Orin. 2009. Concealed questions as concealed questions. Handout of a talk given at the workshop FACQs, Göttingen, June 5-7, 2009.

Percus, Orin. 2010. Uncovering the concealed question (and some shifty types). Handout from SALT 20, Vancouver, April 29, 2010.

Reinhart, Tanya. 1997. Quantifier scope: How labor is divided between QR and choice functions. Linguistics and Philosophy 20: 335-339.

Roelofsen, Floris, and Maria Aloni. 2008. Perspectives on concealed questions. In Proceedings of SALT 18, ed. S. Ito, 601-618. Ithaca, NY: CLC Publications.

Romero, Maribel. 2005. Concealed questions and specificational subjects. Linguistics and Philosophy 28: 687-737.

Romero, Maribel. 2006. On concealed questions. In Proceedings of SALT 16, ed. M. Gibson and J. Howell, 208-227. Ithaca, NY: CLC Publications.

Romero, Maribel. 2007. Connectivity in a unified analysis of specificational subjects and concealed questions. In Direct compositionality, ed. P. Jacobson and C. Barker, 264-305. Oxford: Oxford University Press.

Romero, Maribel. 2010. Concealed questions with quantifiers. In Logic, language and meaning, ed. M. Aloni et al., 21-31. Berlin: Springer.

Rullmann, Hotze. 1995. Maximality in the semantics of wh-constructions. PhD diss., University of Massachusetts at Amherst.

Sauerland, Uli. 2004. The interpretation of traces. Natural Language Semantics 12: 63-127.

Schwager, Magdalena. 2007. Bodyguards under cover: The status of individual concepts. In Proceedings of SALT 17, ed. T. Friedman and M. Gibson, 246-263. Ithaca, NY: CLC Publications.

Schwager, Magdalena. 2008. Keeping prices low: An answer to a concealed question. In Proceedings of Sinn und Bedeutung 12, ed. A. Grønn, 582-596. Oslo: ILOS.

von Stechow, Arnim. 1996. Some remarks on choice functions and LF movement. Manuscript, University of Tüëbingen.

Winter, Yoad. 1997. Choice functions and the scopal semantics of indefinites. Linguistics and Philosophy 20: 399-467. 